\title{
Using weather variability and sociopolitical instability to measure the responses of savings and labour supply
}

\author{
by
}

Solomon Aklilu B.Sc. Eng., B.Sc., M.A.

\author{
A thesis submitted to \\ the faculty of Graduate Studies and Research \\ in partial fulfillment of \\ the requirement for the degree of
}

\author{
Doctor of Philosophy \\ Department of Economics \\ Carleton University \\ Ottawa, Canada \\ (C) Copyright \\ 2005, Solomon Aklilu
}




$\begin{array}{ll}\begin{array}{l}\text { Library and } \\ \text { Archives Canada }\end{array} & \begin{array}{l}\text { Bibliothèque et } \\ \text { Archives Canada }\end{array} \\ \begin{array}{l}\text { Published Heritage } \\ \text { Branch }\end{array} & \begin{array}{l}\text { Direction du } \\ \text { Patrimoine de l'édition }\end{array} \\ \begin{array}{l}\text { 395 Wellington Street } \\ \text { Ottawa ON K1A ON4 }\end{array} & \begin{array}{l}\text { 395, rue Wellington } \\ \text { Ottawa ON K1A ON4 } \\ \text { Canada }\end{array}\end{array}$

Your file Votre référence

ISBN: 0-494-13389-9

Ourfile Notre référence

ISBN: 0-494-13389-9

NOTICE:

The author has granted a nonexclusive license allowing Library and Archives Canada to reproduce, publish, archive, preserve, conserve, communicate to the public by telecommunication or on the Internet, loan, distribute and sell theses worldwide, for commercial or noncommercial purposes, in microform, paper, electronic and/or any other formats.

The author retains copyright ownership and moral rights in this thesis. Neither the thesis nor substantial extracts from it may be printed or otherwise reproduced without the author's permission.
AVIS:

L'auteur a accordé une licence non exclusive permettant à la Bibliothèque et Archives Canada de reproduire, publier, archiver, sauvegarder, conserver, transmettre au public par télécommunication ou par l'Internet, prêter, distribuer et vendre des thèses partout dans le monde, à des fins commerciales ou autres, sur support microforme, papier, électronique et/ou autres formats.

L'auteur conserve la propriété du droit d'auteur et des droits moraux qui protège cette thèse. $\mathrm{Ni}$ la thèse ni des extraits substantiels de celle-ci ne doivent être imprimés ou autrement reproduits sans son autorisation.
In compliance with the Canadian

Privacy Act some supporting forms may have been removed from this thesis.

While these forms may be included in the document page count, their removal does not represent any loss of content from the thesis.
Conformément à la loi canadienne sur la protection de la vie privée, quelques formulaires secondaires ont été enlevés de cette thèse.

Bien que ces formulaires aient inclus dans la pagination, il n'y aura aucun contenu manquant.

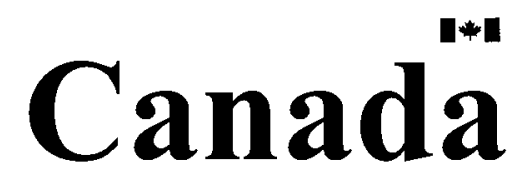




\begin{abstract}
The relationship between weather variability, savings and labour supply; and sociopolitical instability and savings of rural households is explored in three chapters.

In Chapter 1, Living Standards Survey data on agricultural households and weather variability (of regional rainfall) in rural Peru are employed to measure the extent to which farm households use savings and dissavings in response to fluctuations in income. Three cross sections of income and expenditure data on Peruvian farmers were used to construct the savings measures and time-series monthly variable rainfall were also used to proxy transitory income shocks. The regression analysis of income and savings measures on these transitory and the permanent income variables shows the marginal propensity to save out of transitory income to be significantly higher than the marginal propensity to save out of permanent income.
\end{abstract}

In Chapter 2, household responses to income shocks (other than savings) are explored. In most smoothing studies, economists tend to examine savings or consumption behaviours of households while treating other household choices as fixed. Therefore, we considered and examined if those households who take secondary jobs do so for smoothing purposes. In other words, we tested the data to determine if taking secondary jobs is another labor supply mechanism used to smooth consumption in response to income loss. The chapter also studied the way in which labour supply responses of either shifting or increasing working hours enable households to smooth consumption in the face of rainfall 
variability. Using two data sources, we find evidence that the transitory income associated with this shock due to rainfall variability causes households to shift working conditions, but do not increase total working hours. In other words, households reduce farming hours and increase hours worked for wages.

Chapter 3 tests how household saving behaviour explains the response to sociopolitical instability (SPI) in Peru. The mixed character of our data allowed us to test for the effect of different distributional characteristics, in income, on the savings rate and how these distributional aspects interacted with SPI. We find that both the distributional characteristics of income and the SPI have a profound effect on the savings ratio.

In general, there is no dispute about the existence of a considerable amount of uncertainty in the incomes of households in developing countries such as Peru. One way of addressing this problem may be adopting a government policy that deals with income fluctuations. The second approach may be, if households save in "good" times to use their savings or dissave in "bad" times, then there is no efficiency reason for any government interventions. The third measure could be, if households increase their labour supply by either increasing working hours or shifting their labour from non-productive to more productive areas they can smooth consumption through savings. However, the two main sources of uncertainty households are dealing with here, namely weather variability and sociopolitical instability are hardly predictable. Therefore, it will be very difficult or may not be feasible for households in Peru to smooth consumption through savings. We 
believe a combination of policy and conscious household measures may diffuse some of these problems. 


\section{Acknowledgements}

I am truly thankful to Departments of Economics at Carleton University, the University of Windsor, St. Lawrence University and the World Bank.

I would really like to express my deep appreciation to my thesis supervisor, Professor Christopher Worswick, not only for his many painful and yet careful hours in reading so many various versions of the draft, but also for his priceless advice, reassuring encouragement and guidance even financial help throughout the end of the thesis.

Professor Stephen Ferris was also equally instrumental in the review, correction and completion of this thesis. I always remember not only his advice but also the education I received from him through the years. I am also thankful to Professor David Gray, for all the time and effort he put into the completion of the thesis.

I am grateful to Professor Zhiqi Chen, Professor S.B. Park, Dr. Sonia Laszlo, Mr. William Brown of National Oceanic and Atmospheric Administration (NOAA), Mrs. Marge Brooks and Ms. Renee Lortie for their kind help and encouragement.

I wish to dedicate this thesis to my late mother who supported me all my life until she passed away on December 7, 2002. 


\section{Table of Contents}

Acceptance Sheet

Abstract

Acknowledgements

Table of Contents

List of Tables

List of Appendices

Executive Summary

Chapter 1 Weather variability, income shocks and savings of rural households

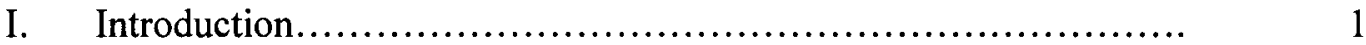

II. Historical and theoretical background............................. 3

III. Derivation of the empirical savings model....................... 11

IV. Inflation adjustment and analysis of savings measures............ 17

V. Data and summary of results.................................. 20

VI. Conclusion.............................................. 26

References..................................................... 28

Tables..............................................................

Appendices........................................................ $\quad 40$ 
Chapter 2 Weather variability, income shocks and labour supply responses of rural households in Peru

I. Introduction................................................ 46

II. Theoretical background....................................... 49

III. Derivation of the model........................................... 51

IV. Estimation methods and strategy................................ 56

V. Data and results............................................... 61

VI. Concluding remarks and policy implications................... 65

References.................................................... 67

Tables.......................................................... $\quad 70$

Appendices.......................................................... $\quad 77$

Chapter 3 Sociopolitical instability, income shocks and savings of rural households

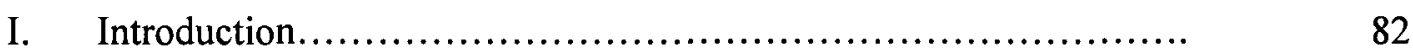

II. Theoretical background............................................ 85

III. Derivation of the model......................................... 87

IV. Data and summary of results................................. 94

V. Conclusion................................................. 98

References....................................................... $\quad 100$

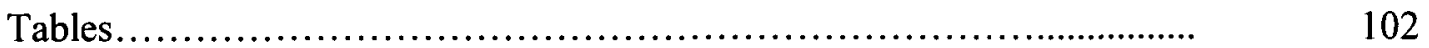

Appendices......................................................... 106

viii 


\section{List of Tables}

Table 1.1 Mean values of savings and income measures, 1985/86

and 1994 individual level observations in four zones............

Table 1.2 Income quartiles and the two adjusted and unadjusted savings measures for 1994 .......

Table 1.3(a) The reduced-form income and savings estimates with downstream run-off consideration.

Table 1.3(b) The reduced-form income and savings estimates without downstream run-off consideration.

Table 1.4(a) Estimates of savings equation with downstream run-off consideration.

Table 1.4(b) Estimates of savings equation without downstream run-off consideration.

Table 1.5 Estimates of savings when transitory income shock is defined as dummy variable.

Table 1.6 Estimates of savings when transitory income is defined as positive and negative shocks

Table 2.1 Estimates of the reduced-form income equation.

Table 2.2 Estimates when hour is total and transitory income is undivided.

Table 2.3 Estimates when hour is total and transitory income is a dummy variable... 
Table 2.4 Estimates when hour is total and transitory income is

divided .......................................................

Table 2.5 Estimates when hour is extra and transitory income is undivided.

Table 2.6 Estimates when hour is extra and transitory income is

a dummy

Table 2.7 Estimates when hour is extra and transitory income is

divided

Table 3.1 Estimates of savings function when SPI is violent.

Table 3.2 Estimates of savings function when SPI is nonviolent

Table 3.3 Estimates of marginal propensity to save at three different values of SPI for each group of household income.

Table 3.4 Estimates of marginal propensity to save at three different values of nonviolent SPI for each income group................. 


\section{List of Appendices}

Appendix 1A Descriptive statistics of household variables.............. 40

Appendix 1B Descriptive statistics of rainfall across regions or rainfall stations......................................................... 41

Appendix 1C Description of variables used in the empirical analysis..... 42

Appendix 1D Identification of regions, rainfall stations and zones for downstream run-off considerations......................... 44

Appendix 1E Downstream run-off calculations........................... 45

Appendix 2A Estimates of the reduced form equation of

total hours.............................................

Appendix 2B Estimates of the reduced form equation of

total extra hour.

Appendix 2D Description and definition of variables.................... 80

Appendix 2E Description of working hours variables................... 81

Appendix 3A Derivation of Equations \#1 through \#5 that forms the regression model with interactions terms based on specific hypotheses..... 106

Appendix 3B Definition and derivation of the various SPI values............ 107

Appendix 3C Typical and chronological examples of sociopolitical disruption in Peru: 1970-1994 


\section{Executive Summary}

The thesis explores the theoretical and empirical relationships between weather variability, sociopolitical instability, savings and working hours. It consists of three parts, each of which contains its own introduction, analysis and conclusion.

Chapter 1 examines the effect of weather variability on rural household savings using a derived savings function that follows the theory of the Permanent Income/Life-cycle hypotheses. The estimated results clearly show that even the behaviour of rural Peruvian farm households towards savings is consistent with the permanent income hypothesis. The marginal propensity to save (MPS) out of transitory income due to rainfall is high, implying that transitory income shocks do not have serious welfare effect on rural Peruvian farmers since they smooth consumption over time. On the other hand, the MPS out of permanent income is small but still greater than zero.

Chapter 2 examines two questions. First, do farm households in rural Peru take on secondary wage employment and increase the overall household members' working hours during unfavourable weather conditions (negative income shocks)? Second, do households take on extra work outside their own farm (or shift their hours of work) because of income-loss due to variability in rainfall, but do not necessarily increase total working hours?

To answer these questions, an intertemporal labour supply model is presented. The first order necessary conditions are derived and used to facilitate the interpretation of the 
analysis. A reduced form hours of work function is employed in order to investigate the labour supply response to transitory income shocks caused by weather variability.

However, very little empirical evidence is found of taking extra jobs or increasing working hours in response to income shocks. On the other hand, we couldn't significantly reject the evidence that indicates income generated from increase in hours of work play an important role in smoothing consumption in any income loss cases.

Our findings in Chapter 1 using the same data proved that households use the natural saving and dissaving mechanism to smooth consumption when faced with income loss due to unfavorable rainfall. In this chapter, we have evidence that some households may have re-allocated their labour from their permanent job (working on the family or rented farm) to the more productive secondary job activity (non-farm activity) after a weather shock.

Chapter 3 examines how and to what extent does income inequality lead to a measured increase in the sociopolitical instability (SPI) and second, does the increase in the SPI have an effect on savings and also on growth? Intuitively, we expect the answer to both these questions would be positive, because unequal societies are more likely to be politically unstable. Greater political instability, that is a higher level of SPI, would increase the value of having future output today and would lower the level of security associated with realizing real returns in the future.

xiii 
To prove or disprove our intuition, therefore, we derived a savings model, which is linear in SPI and income and other equally important variables drawn from a lifetime household utility function. Moreover, all social unrest is not the same in magnitude or character; therefore, we separated SPI into violent and nonviolent types. This separation will allow us to see empirically if they have different effects on household savings.

When we examine the values of the marginal propensity to save with respect to the three measures of SPI based on either violent or nonviolent acts, and with the six income groups, we came to a conclusion that an income distribution which favours the lower and middle-income groups could be a good policy measure. This policy measure is favoured because the bulk of savings in the country come from these groups. Our results also show a great deal of income inequality exists in Peru. Income inequality may increase sociopolitical instability and decrease savings. 


\section{Chapter 1}

\section{Weather variability, income shocks and savings of rural households}

\section{Introduction}

There is a considerable uncertainty in the incomes of households whose livelihoods are based on natural resources, such as farmers who face variable crop yields arising from stochastic rainfall. Government policy that deals with income fluctuation is one way of addressing this uncertainty.

However, if farm households can save in "good times" to overcome the "bad times" there may be no efficiency reason for government intervention. On the other hand, farmers in least developed countries (LDCs) may face obstacles so that consumption smoothing through savings may not be feasible. In these countries, for example, credit markets are far from perfect, and imperfect credit markets prevent households from borrowing. Consequently, in this chapter, we use two cross sections of income and expenditure data, a time series regional rainfall data, and a supplementary cross sectional information set is also used to see whether households in rural Peru use their savings in periods of low rainfall to smooth out consumption.

A number of research papers have been written on savings or consumption behavior of rural households. Paxson (1992), Musgrove (1979), Bhalla (1980), and Wolpin (1982) 
have all contributed to the theory in this chapter. Ever since Paxson (1992) developed an explicit way of measuring transitory income, analysts can test directly the hypothesis that households use savings to smooth consumption. For rural households, Paxson showed that unfavorable weather conditions caused fluctuations in the transitory part of total income and that their relationship with savings could be measured. Following in these footsteps we use several years of rainfall data to measure the transitory part of total household income in rural Peru and then estimate the Marginal Propensity to Save (MPS) out of the variability in transitory income caused by these rainfall shocks. Rainfall is an exogenous factor that can influence income and this will allow us to compute an unbiased estimate of one of the basic parameters of the permanent income hypothesis, the MPS, using the permanent income model of savings.

In this chapter, the historical and theoretical background contained in the development literature upon which this thesis is based and motivated is discussed. An empirical model of savings based on both the permanent and the transitory incomes and set out in Paxson (1992) is derived. The empirical results are then presented and interpreted. 


\section{Historical and theoretical background}

In his famous book The Theory of Interest (First edition 1930), Irving Fisher used a multi-period wealth function to describe the factors causing households to save. It has two characteristics of interest to us. The first is the fact that households' savings decisions are rational and that they save purposefully. The second is that saving does not depend on the income stream alone because individuals have a preference over the time in which they spend their income. In addition to these, Fisher highlights four characteristics of the household's income stream:

(a) the size of the expected real income or wealth;

(b) the household's expected income profile i.e., whether it is constant or varying over time;

(c) the household's composition of income; and

(d) the income risk or uncertainty faced by the household.

Other things being equal, the smaller the household's constant and current income the higher the preference for present over future consumption. Poverty bears down heavily on all portions of a person's expected life by increasing the want for immediate consumption more than the need for savings and future income. This influence of poverty according to Fisher (1930) is partly rational, because of the need to keep up the continuity of life and to maintain the ability to cope with the future; and partly irrational, because the pressure of present needs blinds a person to the needs of the future. 
Keynes (1936), however, stressed that habit formation rather than saving motives are responsible for aggregate savings of households. Keynes further argued that households on average increase consumption as their income increases but not in equal proportions. The marginal propensity to consume (MPC) out of the household's total income is, in general, greater than zero but is also less than one, because households are expected to not consume all of their incomes, therefore, the average increase in income is greater than the average increase in consumption. Apart from short-period changes in the level of income, it is also clear that a higher absolute level of income will tend, as a rule, to widen the gap between consumption and income by increasing savings. The satisfaction of the immediate primary needs of households is usually a stronger motive than the motives towards accumulation, because it only has an impact when a margin of comfort has been attained. These reasons will lead, as a rule, to a greater proportion of income being saved as real income increases. When there is a positive (negative) shock in transitory income it doesn't automatically imply that there will be an equal proportionate increase (decrease) in consumption. Instead, a large portion of it may go to or come from household savings in good or bad times.

Kuznet (1946) empirically demonstrated that the MPC has remained stable in the five decades $1879-88$ to $1919-28$ using U.S. income data and he showed that there was no tendency for the MPC to fall with a secular increase in income. Franco Modigliani and James Duesenberry (1949) then introduced the Relative Income Theory, after Kuznets' (1946) empirical results were established. This theory states that a low-income, doesn't 
make households less likely to save. It also agrees with the basic idea of Fisher's permanent income hypothesis $(\mathrm{PIH})$, in that the lower a household's income, the more intensely the household feels current needs relative to future wants. However, while the permanent income hypothesis does not accept the idea that, the higher permanent income that a household has, the lower the MPC out of the permanent income, Modigliani and Duesenberry (1949) do accept this concept. Moreover, Modigliani (1949) suggested this has to rely on Keynes concept of habit formation rather than other saving motives of households.

In general, the relation between saving and income depends on the hypothesis that utility is a function of relative rather than absolute consumption expenditure. The view that preference is a matter of individual personality alone is certainly untenable, because according to Duesenberry (1949) there are many more similarities than differences between consumption patterns of society as a whole and individual households or household members.

This concept is also echoed and solidified into the true theory of the permanent income hypothesis by Friedman in a different way. He claimed that an individual consumer's "permanent income" and "permanent consumption" play an important role in the theoretical analysis and cannot be observed directly for any individual consumer. Therefore, the best one can do is to observe the actual receipt and expenditures in a finite period (short-time horizon) including some verbal information about future expectations 
given by individuals. The most general form of the theory of the consumption function or the permanent income (according to Friedman) can be stated in three relations: (a) permanent consumption is a function of the interest rate, wealth, consumer preferences, and the permanent income; (b) total income has a permanent and a transitory component; and (c) total consumption is also the sum of permanent and transitory consumption. These three relationships clearly show the relationship between permanent income and permanent consumption, where there is a variety of ways of drawing a given hypothesis about the permanent income and testing it accordingly given data. Consider the following three assumptions, suppose that the correlation between transitory income and permanent income, between transitory consumption and permanent consumption and between transitory income and transitory consumption are zero.

The first two correlation assumptions seem very mild and highly plausible, because one of the many reasons for these will be that the merging of errors of measurement with the transitory component contributes towards the zero correlation assumption. In other words, zero correlation implies that the average transitory component (the algebraic average in which the positive and negative values offset one another) is also the same for values of the permanent component. However, the third assumption that the correlation between transitory income and consumption is zero looks much stronger and needs a thorough investigation and testing. After examining a wide range of empirical results, Friedman summarizes the interpretation of the evidence. The transitory components of a household unit's income have no effect on his/her consumption except as they are 
translated into effects lasting beyond the household unit's time horizon ${ }^{1}$.

Based on the combination of the life cycle and permanent income hypotheses, the assumption that the preferred pattern of allocation of consumption over lifetime and the rate of return on assets remained reasonably stable in time is already empirically proved (Kuznet, 1946). Therefore, the saving-income ratio or the Average Propensity to Save (APS) out of income can now be thought of as a reflection of the household's lifetime habit. Modigliani (1966) showed that current saving decisions of households reflect an endeavour to achieve the preferred allocation of lifetime resources to consumption (and bequests) over the life cycle. He tested inter-country differences in the distribution of income and differences between wage and non-wage incomes. He concluded that there is no evidence of differences in the distribution of income to explain the difference in the saving ratio between countries. He also found no evidence of differences between wage and non-wage incomes to show any systematic differences in the APS out of these two sources of income (1966, p. 197 and 224).

More recently, by combining the two hypotheses, Hall (1978) showed that consumers form estimates of their ability to consume in the long run and then set current consumption to the appropriate fraction of that estimate. The estimate may be stated in the form of wealth, following Modigliani, in which case the fraction is the annuity value of wealth, or as permanent income, following Friedman, in which case the fraction should

\footnotetext{
${ }^{1}$ Evidence supports the highly tentative conclusion that the length of this time horizon is about three years.
} 
be very close to one. Using a time-series data set for the postwar United States, Hall (1978) confirmed that consumption and the marginal utility of consumption both evolve according to a random walk with trend. He also found that the empirical evidence supports a modified version of the life cycle-permanent income hypothesis (1978, p. 971).

Many authors have contributed to the development and application of these theories by taking issues concerning development economics and economic growth in many directions. For instance, Bhalla $(1978,1979)$ published two papers regarding the role of source of income and investment including measurement errors in the permanent income hypothesis in the savings behaviour of rural households. He found that poor households save more and rich households save less, in response to improved investment opportunities (1978, p. 259). He also tested the proportionality hypothesis of the PIH using two year panel data by explicitly allowing for the presence of measurement errors in all variables in his model, namely income, consumption, and saving. The empirical estimation of the variances of these errors was possible due to the availability of independent estimates of consumption, savings, and income (1979, p. 295). In doing so, a major and controversial aspect of the PIH was strongly rejected by his data (a panel survey of 4,118 households in rural India). The elasticity between permanent components was found to be less than one. In addition, his results also refuted the proposition that consumption is proportional to permanent income. 
Musgrove (1979) also estimated a model that separates the direct and indirect effects on consumption of a series of observable characteristics of households. These household characteristics are highly correlated with permanent income and also are presumed to affect consumption directly. Therefore, he used defined vectors of variables like classes of occupation of the head of the household, combinations of age and formal schooling of the head of the household, educational levels and age groups of the household very carefully. He also showed, for the first time, that these variables including other life cycle stage dummies can be used as proxies to the permanent income because they have no direct effect - apart from their indirect influence through permanent income - on consumption (1979, pp. 355-58). His findings were consistent with all of Friedman's assumptions except that of a strong rejection of the proportionality hypothesis.

Wolpin (1982) was the first to use and present a strong test of the two key propositions of the permanent income hypothesis, that permanent income elasticity due to consumption of unity, and a transitory income elasticity of zero. These results are found without using a residual concept of transitory income and, therefore, asserted that the residual cannot be free of all permanent elements. In particular, Wolpin (1982) used a three-year income and consumption panel data set to look at the impact of permanent and transitory weather patterns on the income and consumption of rural Indian farm households. The test results provided strong support for the notion that transitory income does not affect consumption, and mild support for the notion that the elasticity of consumption with respect to permanent income is unity. Moreover, the results are supportive of the 
permanent income view as was put forward by Friedman.

A very important and relatively recent paper is Paxson's (1992) study of rice farmers in Thailand, which shows the extent to which farm households use savings and dissavings to smooth consumption in response to unexpected shocks to income by utilizing time-series information on regional rainfall as an instrument.

This chapter follows the Paxson (1992) study in circumventing the problem of distinguishing transitory income and measurement errors by recognizing the difficulty of directly testing hypotheses that depend on the distinction between measurement error and transitory income. Thus because of the difficulties associated with measuring permanent income, Paxson (1992) focused on the indirect proxy of transitory income through rainfall shocks. Rainfall variation can have a positive or negative effect on crop yields resulting in transitory income variation. Moreover, the deviation of each year's rainfall from its mean has a zero mean that is serially uncorrelated and thus unpredictable. Therefore, the change in income associated with an above or below average level of rainfall will be transitory, with no direct effect on permanent income. Paxson's results also confirm Friedman's view of the permanent income hypothesis. 
The following model and discussion is based on Paxson (1992) and Deaton (1997). A lifetime utility function that is additively separable over time and that has constantabsolute-risk-aversion (CARA) can be represented by a savings equation, which is linear, in permanent and transitory income. One such example is:

$$
S_{i r t}=\alpha_{0}+\alpha_{1} Y_{i r t}^{P}+\alpha_{2} Y_{i r t}^{T}+\alpha_{3} V A R_{i r}+\alpha_{4} W_{i r t}+e_{i r t}
$$

Where $\left(S_{i r t}\right)$ is the total household savings. Permanent income $\left(Y_{i r t}^{p}\right)$ is defined over a short time horizon, and it is the expected income of households conditioned on the resources and information of the household at the beginning of the period. Transitory income $\left(Y_{i r t}^{T}\right)$, on the other hand, is the difference between realized (after income shock if any) and expected income (had there been no shock). The subscript to both variables represent the incomes of household $\mathbf{i}$ in region $\mathbf{r}$ at time $\mathbf{t}$. The variability of the household's income is captured by a set of variables that measure the variability of regional rainfall. More variable rainfall implies more variable income. This variable does not vary across households within the same region or across survey years and is denoted by $V A R_{i r}$. The life-cycle stage of the household, which is denoted by $W_{i r}$, represents the number of household members in different age and sex groups.

The total measured income $(\mathrm{Y})$ is the sum of its transitory and permanent components. According to the permanent income hypothesis, the coefficients $\alpha_{1}$ and $\alpha_{2}$, the 
propensity to save out of permanent income and the propensity to save out of transitory income, would approach zero and one respectively. Therefore, if we find evidence that $\alpha_{1}$ is less than $\alpha_{2}$, i.e., a high portion of the transitory income is saved, the permanent income hypothesis suggests that households are acting so as to smooth their consumption relative to income. Although, at least theoretically, the sign of $\alpha_{3}$ is not clear, empirical tests (Paxson, 1992, Deaton 1997) show that it can provide a control for information on whether households with riskier income streams save more on average than those with more stable income.

The estimation of equation (1.1) requires additional assumptions in order to identify the effects of transitory and permanent income, because these variables are unobserved. For example, let us suppose that we substitute $Y^{T}=Y-Y^{P}$, so that equation (1.1) can be written as:

$$
S_{i r t}=\alpha_{0}+\alpha_{2} Y+\left(\alpha_{1}-\alpha_{2}\right) Y^{P}+\alpha_{3} V A R_{i r}+\alpha_{4} W_{i r t}+e_{i r t}
$$

If transitory income is the residual term, these equations can be estimated from a single cross-section of data, if suitable instruments for permanent income can be found. It may be that the chosen determinants of the permanent income are actually related to permanent income in the survey year when the data used comprises only one or few cross-sections. Various techniques have been used by a number of authors: Musgrove $(1978,1979)$, used assets and four age groups with four education levels that cover seven cities of three South American countries as an instrument. Bhalla $(1979,1980)$ used 
lagged income and average income over the previous years as an instrument to investigate whether poor households in rural India save more and rich households save less, in response to an increase in investment opportunities. Wolpin (1982) for the case of India used long-run average rainfall (that is historical not the current regional average) as an instrument. Furthermore, to compute the estimates of the basic parameter of Friedman's permanent income hypothesis and the permanent income elasticity of consumption he used the time-series rational expectation representation and the more usual cross-sectional instrumental variable estimation strategy.

We also adopted the following equations that Paxson (1992) employed. These are estimable versions of the permanent income and the transitory income:

$$
\begin{aligned}
& Y_{i r t}^{P}=\beta_{t}^{P}+\beta_{0 r}+\beta_{1} X_{i r t}^{P}+\varepsilon_{i r t}^{P} \\
& Y_{i r t}^{T}=\beta_{t}^{T}+\beta_{2} X_{r t}^{T}+\varepsilon_{i r t}^{T}
\end{aligned}
$$

In estimating permanent income, $X_{i r t}^{P}$ represents a vector of household specific variables that include land-ownership dummies, number of household members and characteristics including 13 age and education level groups. $\beta_{0 r}$ is a vector of fixed region specific variables reflecting such things as locational advantage. $\beta_{t}^{P}$ is a time varying intercept that is common to all households, and $\varepsilon_{i r}^{P}$ is a random error whose expected value is equal to zero. 
In equation (1.4), $X_{n}^{T}$ consists of both the deviations from the average (stdRj) and its square values (Rjsq) of regional rainfall at a given time, in each of the four seasons.

The quantity of water available increases for downstream regions when there is rain in the upstream regions. We are going to account for downstream run-off for some regions. For more explanation and calculation of downstream run-off consideration refer to Appendix 1D and 1E. The idea of downstream run-off consideration is new ${ }^{2}$.

Paxson (1992) did not account for downstream effects. This could be because Thailand is very flat compared to Peru, instead Paxson (1992) assigns a certain number of rainfall stations for each region and calculates the regional specific rainfall variations using data from those stations.

$\beta_{t}^{T}$ is a time varying intercept common to all households, and the expected value of the random error $\varepsilon_{i n}^{T}$ is equal to zero.

From equations (1.3) and (1.4) and the identity that total income is the sum of transitory and permanent income, we can form the following equation for total income.

$$
\begin{aligned}
Y_{i r t} & =Y_{i r t}^{P}+Y_{i r t}^{T}=\beta_{t}^{P}+\beta_{0 r}+\beta_{t}^{T}+\beta_{1} X_{i r t}^{P}+\beta_{2} X_{r t}^{T}+\varepsilon_{i r t}^{P}+\varepsilon_{i r t}^{T} \\
& =\beta_{t}+\beta_{1} X_{i r t}^{P}+\beta_{2} X_{r t}^{T}+\varepsilon_{i r t}
\end{aligned}
$$

\footnotetext{
${ }^{2}$ We would like to acknowledge Dr. Laszlo of McGill University for suggesting the idea of run-off to us.
} 


$$
\text { Where, } \beta_{t}=\beta_{0 r}+\beta_{t}^{P}+\beta_{t}^{T} \text { and } \varepsilon_{i r t}=\varepsilon_{i r t}^{P}+\varepsilon_{i r t}^{T}
$$

Equations (1.3) and (1.4) can also be substituted into equation (1.1) to form the following unrestricted reduced- form of the savings equation. To derive the required reduced-form equation we start from equation (1.1):

$$
\begin{aligned}
S_{i r t} & =\alpha_{0}+\alpha_{1} Y_{i r t}^{P}+\alpha_{2} Y_{i r t}^{T}+\alpha_{3} V A R_{i r}+\alpha_{4} W_{i r t}+e_{i r t} \\
S_{i r t} & =\alpha_{0}+\alpha_{1}\left[\beta_{t}^{P}+\beta_{0 r}+\beta_{1} X_{i r t}^{P}+\varepsilon_{i r t}^{P}\right]+\alpha_{2}\left[\beta_{t}^{T}+\beta_{2} X_{r t}^{T}+\varepsilon_{i r t}^{T}\right] \\
& +\alpha_{3} V A R_{i r}+\alpha_{4} W_{i r t}+e_{i r t} \\
S_{i r t} & =\left[\alpha_{0}+\alpha_{1}\left(\beta_{t}^{P}+\beta_{0 r}\right)+\alpha_{2} \beta_{t}^{T}\right]+\alpha_{1} \beta_{1} X_{i r t}^{P}+\alpha_{2} \beta_{2} X_{i r t}^{T} \\
& +\alpha_{3} V A R_{i r}+\alpha_{4} W_{i r t}+\left[e_{i r t}+\alpha_{1} \varepsilon_{i r t}^{P}+\alpha_{2} \varepsilon_{i r t}^{T}\right]
\end{aligned}
$$

Therefore, the reduced-form equation can be written as:

$$
S_{i r t}=\gamma_{t}+\gamma_{1} X_{i r t}^{P}+\gamma_{2} X_{i r t}^{T}+u_{i r t}
$$

Where, $\gamma_{t}=\alpha_{0}+\alpha_{1}\left[\beta_{t}^{P}+\beta_{0 r}\right]+\alpha_{2} \beta_{t}^{T}$

$$
\begin{aligned}
& u_{i r t}=e_{i r t}+\alpha_{1} \varepsilon_{i r t}^{P}+\alpha_{2} \varepsilon_{i r t}^{T} \\
& \gamma_{1}=\alpha_{1} \beta_{1} \text { and } \gamma_{2}=\alpha_{2} \beta_{2} .
\end{aligned}
$$

Notice the reduced- form savings equation doesn't contain $V A R_{i r}$ and $W_{i r}$ because they both are highly correlated with the transitory and permanent components of the model (Paxson, 1992, p.18), therefore, the more they look alike, the more imprecise is the estimate of their relative effects on savings. However, they could be included in the savings equation when we use estimated approximations of the permanent and the 
transitory incomes.

Notice also from the above equations that if the permanent income hypothesis is true then $\alpha_{1}=0$ must imply that $\gamma_{1}=0$. Moreover, $\alpha_{2}=1$ implies that $\gamma_{2}=\beta_{2}$, where $\alpha_{1}$ and $\alpha_{2}$ are marginal propensity to save out of the permanent and the transitory incomes respectively. These two tests imply collectively that transitory rainfall affects savings the same way as it affects income but it must have no effect on consumption. In particular the test that $\gamma_{2}=\beta_{2}$ implies that the effect of a transitory rainfall shock on savings should be identical to the effect produced on income. To solve the above problem and test our hypotheses we need to:

1. Estimate equations (1.3) and (1.4) the components of the total income equation, and equation (1.8) the reduced form of savings equation.

2. Estimate equation (1.9) the general savings equation by a two-step procedure.

First, we use the estimated results of equation (1.3) and (1.4) and denote estimates of permanent and transitory incomes as $\hat{Y_{i r t}^{P}}$ and $\hat{Y_{r t}^{T}}$ respectively. As a second step, we regress the following savings equation:

$$
S_{i r t}=\alpha_{0}+\alpha_{1} \hat{Y_{i r t}^{P}}+\alpha_{2} \hat{Y_{i r t}^{T}}+\alpha_{3} V A R_{i r}+\alpha_{4} W_{i r t}+\alpha_{5} \hat{\varepsilon_{i r t}}+e_{i r t}
$$

Where, $\hat{\varepsilon_{i r t}}=Y_{i r t}-\left(\hat{Y_{i r t}^{P}}+\hat{Y_{i r t}^{T}}\right)$ 


\section{Inflation adjustment and analysis of savings measures}

The two major data-sets we are using, that are collected by the help and active participation of the World Bank, cover approximately 98\% (Instituto Nacional de Estadistica e Informacion-INEI)) of farm households in Peru. Therefore, the information about income, expenditure and the like, provided in them combined with our definition of permanent income in the short-term horizon, allows us to use at least three types of savings measures (Paxson, 1992, p. 19). Moreover, in these types of data, as any such data from LDCs it is likely that income to be severely under-reported relative to expenditure, resulting in very low savings figures. Therefore, we used inflation adjustments to bring savings figures much closer to national-accounts measures of household savings as reported by the World Bank World Tables (1985, 1986 and 1994).

The first saving measure, SAVE1, is defined as the difference between income and expenditure on all goods and services. This definition corresponds to the concept of savings used in the national income accounts. The second saving measure, SAVE2, is defined as the difference between income and expenditure on all goods and services excluding consumer durables, such as, vehicles, household and recreational equipments, furniture, clothing, foot wear, and educational expenses. The third and last saving measure, SAVE3, is defined as all purchases minus the sales of real and financial assets in the month before the survey (Paxson, 1992, p. 20). 
Again, according to Paxson (1992) the saving measures SAVE1, SAVE2 and SAVE3 are monthly values and have to be adjusted for inflation due to the problems mentioned above, using the following technique:

Let $\mathrm{X} 1 \mathrm{i}$ be expenditure on all monthly items, and $\mathrm{X} 2 \mathrm{i}$ be average monthly expenditure on annual items, also let Yi be the average monthly income. If AdjSAVEi and AvgXli are adjusted values of saving and average monthly expenditure respectively and saving is generally defined as $\mathrm{Yi}-\mathrm{X} 1 \mathrm{i}-\mathrm{X} 2 \mathrm{i}$, then $\mathrm{AvgX} 1 \mathrm{i}=\mathrm{bX} 1 \mathrm{i}$, where $\mathrm{b}$ is the bias or adjustment factor whose value is between 0 and 1 . For this value of $b$ adjusted saving will always be greater than unadjusted saving and can be calculated as:

$$
\begin{aligned}
& \text { AdjSAVEi }=\text { SAVEi }+(X 1 i+X 2 i-b X 1 i-b X 2 i)=\operatorname{SAVEi}+(1-b)(X 1 i+X 2 i) \\
& \text { Where, } i=1,2,3
\end{aligned}
$$

The reason that SAVE3 should also be adjusted is because it is a measure of the change in assets in the month before the survey; therefore, inflation during the survey can affect the relationship between the fraction of income saved as an asset and the total household income $\mathrm{e}^{3}$.

\footnotetext{
${ }^{3}$ For a complete derivation of the adjustment factor see Paxson (1992), p. 21. To calculate its value for the two years (1985/86 and 1994) we used the CPI values provided by INEI in the month before the survey.
} 


\section{Data and summary of results}

We use living standards survey data drawn from the year's 1985/86 and 1994 together with some supplementary information from the 1991 Peru Living Standards Survey (PLSS). Detailed information on the demographic composition of households, amounts of income by source, amounts of consumption by expenditure type, including some asset holdings was collected independently. In addition to the two PLSS data sets, 28 years of time-series data on regional rainfall in 18 different regional weather stations was obtained from the United States Department of Commerce, National Oceanic and Atmospheric Administration (NOAA) National Data Center.

Statistical Institute of Peru (INEI) implemented the collection of the 1985/86 surveys with the technical and financial support of the World Bank and The Central Reserve Bank of Peru. Initially, 5024 households were selected at the national level with 2284 of these households being from rural Peru with the exception of the departments of Ayacucho, Apurimac and Huancavelica, which were considered emergency zones because of terrorist activity. Overall, $94 \%$ of the total population of Peru (19.8 million in 1986) lives in the surveyed area. According to the World Bank specification report, the survey was done simultaneously in all selected areas during 12 consecutive months from the middle of July 1985 to the middle of July 1986 . The data was then checked for errors, which lead to some being eliminated for not meeting the minimum requirement. The remaining data are considered good and highly consistent. In addition to the $4.5 \%$ 
average monthly inflation rate, the Consumer Price Index rose by more than $70 \%$ during the application of the $1985 / 86$ PLSS.

The work for all stages of the 1991 PLSS was conducted by the Peruvian research enterprise Cuanto S.A., with only the technical and financial assistance of the World Bank. Because of financial limitations, the geographic field of study did not cover the entire national territory. The rural mountain areas, which are historically the most deprived sections of the country, the central mountains, which are recognized as dangerous zones for reasons of terrorist activity, and the forests regions were excluded due to costs. The central urban was excluded for being very close to Metropolitan Lima. The domain of study then included, only the North and the South (urban coast and mountain, and rural mountain), the Center (urban and rural mountain), and Lima (Metropolitan), which in total cover only $70 \%$ of the 22 million Peruvian populations in 1991. The use of this information from the 1991 data in our work is very limited.

The fieldwork for the survey was performed during the months of October and November of 1991. The level of political strife of 1991 was greater than what it was when the $1985 / 86$ survey was conducted, but less severe than the environment in 1990. Moreover, in 1991 the monetary unit was changed from Intis to Nuevos Soles. Unlike the $1985 / 86$ surveys, all monetary values of expenses and income are expressed in constant Nuevos Soles from the first week of October in 1991, based on the prices in Metropolitan Lima. Please note here that in October 1991, 1000 Intis was exchanged for one Nuevos Soles 
and 0.86 Nuevo Soles equaled $\$ 1$ (one United States dollar).

Just like the 1991 PLSS, the 1994 PLSS was designed and conducted by Cuanto S.A., but both the World Bank and the Interamerican Development Bank now provided the technical and financial support. However, unlike the 1991 PLSS, the 1994 PLSS covered the better part of the country (almost closer to the 1985/86 PLSS). It provides data on 3623 households from all private dwellings and their inhabitants in Peru. The entire sample consists of 3544 dwellings (a dwelling may contain one or more than one households) of which 820 are from Metropolitan Lima, 1380 are from other urban areas and 1344 from rural areas, which resulted in a final sample of 3623 households. We are using data only on those 1338 rural households or 1344 dwellings. Values of aggregate household expenditure and income have been deflated to correct for inflation. During the survey period the national price rose by approximately $3 \%$ per annum. Monthly price data, for 16 cities in all regions, was provided by the Peruvian National Statistical Institute (Instituto Nacional de Estadistica e Informacion-INEI). Each price is then deflated relative to its value in Metropolitan Lima in Nuevos Soles of June 1994.

The second type of data includes time-series information on regional rainfall over the period 1973 - 2000 from 18 weather stations or regions throughout the country. The United States Department of Commerce, NOAA, Environmental Satellite data and Information Service collected it. Weather stations were then matched with the household

\footnotetext{
4 To change the values of $1985 / 86$ data in to June 1994 monetary values we used three steps: values of the currency were changed from Intis to 1991 Nuevos Soles, then we changed prices to 1994 value.
} 
information to provide regional weather information for each household in the sample.

The two-stage Ordinary Least Square (2SLS) and bootstrap estimation methods are employed on equation (1.9). The two estimates were quite similar and showed negligible differences; therefore, we reported only the latter. For credit constraint purposes, we also needed to use a dummy variable and variables representing to the positive and the negative transitory income shock. Moreover, this will help us see the effect of these different aspects of the transitory income shocks on savings. The results of these estimates are summarized as follows.

Table 1.1 presents comparisons of unadjusted and adjusted savings measures. Mean values are presented for the four different zones in the 18 regions and for the whole country ${ }^{5}$. Average inflation adjustment factors were assigned to both data based on the average monthly inflation rates and the consumer price indices. As one can see from table 1.1, the inflation adjustment has a much higher effect on savings in 1985/86 than in 1994; however, the biases produced by inflation in both years are not trivial.

Table 1.2 shows how the inflation-adjustment changes the savings rate in 1994 for the four income groups. It solidifies the idea and importance of inflation-adjustments, where clearly in the poorest households, the inflation-adjustment increased the savings rate by about double the amount for the richest households in the survey.

\footnotetext{
${ }^{5}$ We divided Peru into 18 geographical regions and four different zones based on the distribution and location of rainfall stations available.
} 
Regression estimates of reduced-form income and savings equations (1.5 and 1.8), with downstream run-off consideration, are shown in table 1.3(a). The income equation results indicate that the transitory rainfall variables are jointly significant in the reduced-form income and savings equations. The other striking result is that the landownership variables for all three of the savings measures are insignificant (see Test 2 F-test p-values at the bottom of table 1.3(a)). These two test results do not provide full support for a strong version of the permanent-income hypothesis.

Table 1.4(a) shows the estimates of the restricted savings equation (1.9). The estimate of the MPS out of transitory income $\left(\alpha_{2}\right)$ ranges from 0.41 to 0.88 and the estimate of the MPS out of permanent income $\left(\alpha_{1}\right)$ ranges from 0.19 to 0.31 for all savings measures. This significantly large difference between these two results supports the idea that rural households save a higher percentage of transitory income than nontransitory income. Since SAVE2 is defined as income minus expenditure excluding durables, it treats durable goods as savings, therefore, one can expect to get a greater MPS for SAVE2 than for SAVE1. The result from the analysis is $\mathbf{0 . 8 8}$ for SAVE2, and 0.84 for SAVE1, which is consistent with this prediction. Moreover, the MPS out of permanent income for SAVE3 is the lowest at 0.19. These results are consistent with those in Paxson (1992), which suggest that although all transitory income is saved not all permanent income is consumed. 
Since the error term or unexplained income is calculated as $\hat{\varepsilon_{i r t}}=Y_{i r t}-\hat{Y_{i r t}^{P}}-\hat{Y_{i r}^{T}}$, it contains both transitory and permanent components of income; therefore, the estimated MPS out of unexplained income is difficult to interpret. However, the coefficients on this error term for the three savings measures should be between $\alpha_{1}$ and $\alpha_{2}$ and can be used to see the extent to which measurement error affected the two main coefficients with respect to the three savings measures. The MPS due to unexplained income for SAVE1 is 0.49 (which is between 0.27 and 0.85 ), and for SAVE2 it is 0.51 (between 0.31 and 0.88 ) but for SAVE3 it is 0.28 (between 0.19 and 0.41 ), almost half of those two values above. This is consistent not only with there being greater measurement error in SAVE3 but also with the fact that the error coefficient being between the coefficients of the permanent and the transitory income. For the above reason, therefore, it is always important to use explicit measures of transitory income and permanent income separately to test the lifecycle/permanent income models.

From table $1.4(\mathrm{~b})$, of all variables representing $V A R_{i r}$, only stdR2 is negatively related to all savings measures, on the other hand both $\mathrm{R} 2 \mathrm{r}$, and $\mathrm{R} 2 \mathrm{rsq}$, have, not only a positive relationship to income and all savings measures, but also increase them by a significant positive amount (see table 1.3(a)). R4r tend to increase income by a certain amount (table 1.3(a)) but stdR4 seems (however small) to have a negative relationship with SAVE1 and SAVE2. R1r increases income while depressing savings (table 1.3(a)), however; stdR1 significantly increases SAVE1 and SAVE2 (table 1.4(a)). R3r decrease both income and 
all savings (table 1.3(a)), including stdR3, which has a negative relationship with SAVE1 and SAVE2. These relationships between variables and estimation results of tables 1.3(a) and table 1.4(a) indicate that household income and savings are affected separately by seasonal rainfall variability. However, the overall effect of rainfall variability seems to have clear and direct effect on income and on savings of households, yet show no clear relationship between income variability and fluctuations in savings simultaneously.

The effect of the life-cycle stages of the household (the age structure and education level) on income and the savings measures is minimal and in most cases very insignificant. All variables except adult1864 depress income and all savings (table 1.4(a)).

Tables 1.5 and 1.6 report estimation results of the savings measures when the transitory income of households is defined as a dummy variable and divided into negative and positive values respectively. We considered this approach for two reasons. First, we wanted to separate the positive and negative transitory shocks and confirm our previous result and solidify our findings. The second and most important reason is for credit constraint purposes. Our results in both tables are consistent to our findings that are reported in table 1.4(a). That is, variability of regional rainfall variables, stdR 4 and stdR2 tend to depress savings while stdR 3 and stdR 1 tend to affect savings positively (tables 1.5 and 1.6). Most of the life-cycle stages of the household variables, except adult1864, tend to affect savings negatively. These confirm and solidify our previous findings that although all permanent income is not saved, all is not consumed either. 
The results of this paper clearly show that the behaviour of Peruvian farm households towards savings is generally consistent with the permanent income hypothesis. The MPS out of transitory income due to rainfall is significantly greater than zero and in the range of 0.41 to 0.88 , implying that households are able to smooth transitory income shocks. These results mean that negative shocks may not have serious welfare effect on Peruvian farmers because they smooth consumption over time. On the other hand, the MPS out of permanent income is small but still greater than zero. Therefore, while not all of the predictions of the PIH are met, the evidence indicates that these households are able to smooth 41 to $88 \%$ of their income shocks.

The types of farming and/or livestock activity undertaken by the Peruvian rural population are cash crops at lower altitudes (coffee on the eastern slopes of the Andes) and rural valleys (fruits and vegetables), subsistence farming and livestock at very high altitudes (Laszlo, 2005, p.12). However, more than $98 \%$ of rural households surveyed in $1985 / 86$ and about $99 \%$ in 1994 reported to have produced two or more of the following crops: coffee, cotton, sugarcane, rice, potatoes, corn, plantains, grapes, oranges and coca (PLSS 1985/86, PLSS 1994). Therefore, we agree with Paxson's (1992) conclusion that if the transitory world price of these products increases or declines it could have a serious welfare effect on Peruvian economy as well as rural savings. For example, transitory decline in world prices of these products may result in a reduction in farm income, which 
in turn could lead to a large decrease in savings of the farm sector. However, a government tax on export prices of these farm products may have a smaller effect on rural transitory savings, because the tax will have a permanent and direct effect on the prices and not on household savings. 


\section{References}

Surjit S. Bhalla, "Measurement Errors and the Permanent Income Hypothesis:

Evidence From Rural India," The American Economic Review, Vol. 69 No. 3, June $1979,295-307$

-----.-, “The Role of Sources of Income and Investment Opportunities in Rural

Savings," Journal of Development Economics, Vol. 5, 1978, 259-81

Olivier Jean Blanchard and Stanley Fisher, Lectures on Macroeconomics, (The MIT Press, 1989.)

Lisa A. Cameron and Christopher Worswick, "The Labor Market as a Smoothing

Device: Labor Supply Responses to Crop Loss," Review of Development Economics, Vol. 7 No. 2, 2003 327-341

Angus Deaton, The Analysis of Household Surveys, A Microeconometric Approach to Development Policy, Published for the World Bank, The Johns Hopkins University Press, Baltimore and London, July 1997.

James Duesenberry, Income, Saving and the Theory of Consumer Behavior

(Cambridge, Harvard University Press, 1949.)

Irving Fisher, The Theory of Interest (NY, Augustus Kelly, First edition 1930 and the 1961 ed.)

Milton Friedman, $A$ Theory of the Consumption Function, (Princeton University Press, 1957.)

---------, 'Windfalls, the 'Horizon' and Related Concepts in the Permanent Income Hypothesis," in Carl Christ (ed.), Measurement in Economics: Studies in Mathematical Economics and Econometrics in Memory of Yehuda Grunfeld, 
(Stanford, Stanford University Press, 1963.)

Kwabena Gyimah-Brempong and Thomas L. Traynor, "Political Instability, Investment and Economic Growth in Sub-Saharan Africa," Journal of African Economics, Vol. 8 No. 1 pp. 52-86

Robert E. Hall, "Stochastic Implications of the Life Cycle-Permanent Income Hypothesis: Theory and Evidence," Journal of Political Economy, 1978, vol. 86, no. 6

William Hamburger, "The Determinants of Aggregate Consumption," Review of Economic Studies, 1955, Vol. XXII, No. 57, 23-34

-.-...-., "The Relation of consumption to Wealth and the Wage Rate," Econometrica, Vol. XXIII, January 1955, 1-17

J. Maynard Keynes, The General Theory of Employment, Interest and Money (NY, Harcourt Brace, 1936)

Anjini Kochar, "Smoothing Consumption By smoothing Income: Hours-of-work Responses to Idiosyncratic Agricultural Shocks in Rural India," The Review of Economics and Statistics, February 1999, Vol. 81(1): 50-61

Simon Smith Kuznets, National Income; a Summary of findings, National Bureau of Economic Research, inc., 1946.

Sonia Laszlo, "Self-Employment Earnings: an Empirical analysis of Non-Farm Activities in Rural Peru," Journal of Development Studies, 2005, Vol. 41(7): 1247-1287.

Thomas Mayer, Permanent Income, Wealth and Consumption, (Los Angeles, Berkeley 1972) 
Franco Modigliani, "Fluctuations in the Savings-Income Ratio: A Problem in

Economic Forecasting," Studies in Income and Wealth, Vol. 11 (NY, National Bureau of Economic Research, 1949)

--------, "The Life Cycle Hypothesis of Saving, The Demand for Wealth and The

Supply of Capital," Social Research, Vol. 33, Summer 1966, 160-217

-.-.----, "The Life Cycle Hypothesis of saving and Inter country Differences in the Saving Ratio," in W. Eltis, M. Scott and J. Wolfe (eds.) Induction, Growth and Trade, Essays in Honor of Sir Roy Harrod (Oxford, Clarendon Press, 1970) 197225

Franco Modigliani and Robert Ando, "Tests of The Life Cycle Hypothesis of Savings," Oxford University, Institute of Economics and Statistics, Bulletin, Vol. 19, May $1957,99-124$

--------, "The 'Life Cycle' Hypothesis of Saving, “ American Economic Review, Vol. LII, March 1963, 55-84

Philip Musgrove, "Permanent Household Income and Consumption in Urban South America," American Economic Review, Vol. 69 No. 3, June 1979

Christina H. Paxson, "Using Weather Variability To Estimate the Response of Savings to Transitory Income in Thailand," American Economic Review, Vol. 82 No. 1, March 1992

Kenneth I. Wolpin, “A New Test of the Permanent Income Hypothesis: The Impact of Weather on the Income and Consumption of Farm Households in India," International Economic ReviewVol. 23 No. 3, October 1982 
Peru Living Standards Measurement Survey (PLSS) 1985-86, Basic Information, Poverty and Human Resources Division, The World Bank, December 1993

--------, (PLSS) 1991, Basic Information, Poverty and Human Resources Division, The World Bank, December 1993

--------, (PLSS) 1994, Supplemental Information, Development Research Group

Poverty and Human Resources, The World Bank, August 1998.

National Data Centers, U.S. Department of Commerce, National Oceanic and Atmospheric Administration (NOAA), National Environmental Satellite-Data and Information Service. Surface Hourly Abbreviated 6, 12 and 24 Hour Liquid Precipitation Report in Inches and Hundredths on Peruvian Sites.

The World Bank World Tables (1985, 1986 and 1994) 
Table1.1 Mean values of monthly savings and income measures, 1985/86 and 1994 individual level observations, in the four zones.

(Number of observations $=27,130$ in both years)

\begin{tabular}{|c|c|c|c|c|c|c|c|c|}
\hline \multirow{2}{*}{ Zones } & \multirow[b]{2}{*}{ Observations } & \multicolumn{2}{|c|}{ SAVE1 } & \multicolumn{2}{|c|}{ SAVE2 } & \multicolumn{2}{|c|}{ SAVE3 } & \multirow[b]{2}{*}{ Income } \\
\hline & & Unadjusted & Adjusted & Unadjusted & Adjusted & Unadjusted & Adjusted & \\
\hline \multicolumn{9}{|c|}{ 1. Adjustment factor $(b)=98 \%[1985 / 86]$} \\
\hline North Western & 757 & $\begin{array}{l}55.10 \\
(2046)\end{array}$ & $\begin{array}{l}110.25 \\
(4094)\end{array}$ & $\begin{array}{c}62.31 \\
(2318)\end{array}$ & $\begin{array}{c}99.03 \\
(3682)\end{array}$ & $\begin{array}{l}111.32 \\
(613)\end{array}$ & $\begin{array}{c}1.57 \\
(6.25)\end{array}$ & $\begin{array}{l}75.50 \\
(2728)\end{array}$ \\
\hline North Eastern & 3401 & $\begin{array}{l}244.50 \\
(7126)\end{array}$ & $\begin{array}{l}247.40 \\
(7126)\end{array}$ & $\begin{array}{l}232.30 \\
(7125)\end{array}$ & $\begin{array}{l}235.20 \\
(7124)\end{array}$ & $\begin{array}{r}421.80 \\
(5686)\end{array}$ & $\begin{array}{c}71.50 \\
(567)\end{array}$ & $\begin{array}{l}375.70 \\
(7121)\end{array}$ \\
\hline South & 5197 & $\begin{array}{l}132.16 \\
(310)\end{array}$ & $\begin{array}{l}128.31 \\
(308)\end{array}$ & $\begin{array}{l}164.90 \\
(243.50)\end{array}$ & $\begin{array}{l}161.03 \\
(239.60)\end{array}$ & $\begin{array}{l}65.49 \\
(28.24)\end{array}$ & $\begin{array}{l}10.40 \\
(30.40)\end{array}$ & $\begin{array}{l}199.84 \\
(1739)\end{array}$ \\
\hline Centre & 8493 & $\begin{array}{l}1084.50 \\
(41926)\end{array}$ & $\begin{array}{c}1850.80 \\
(71553)\end{array}$ & $\begin{array}{l}1229.10 \\
(47515)\end{array}$ & $\begin{array}{c}1807.50 \\
(69876)\end{array}$ & $\begin{array}{l}25.14 \\
(82.90)\end{array}$ & $\begin{array}{l}4.17 \\
(18.00)\end{array}$ & $\begin{array}{l}14467.67 \\
(55909)\end{array}$ \\
\hline Peru & 17848 & $\begin{array}{l}1020.56 \\
(47447)\end{array}$ & $\begin{array}{c}1530.90 \\
(22120)\end{array}$ & $\begin{array}{c}765.32 \\
(10603)\end{array}$ & $\begin{array}{c}1020.47 \\
(14747)\end{array}$ & $\begin{array}{c}71.23 \\
(579.6)\end{array}$ & $\begin{array}{r}11.38 \\
(72.02)\end{array}$ & $\begin{array}{l}1022.50 \\
(47475)\end{array}$ \\
\hline \multicolumn{9}{|c|}{ 2. Adjustment factor $(b)=99 \%[1994]$} \\
\hline North Western & 752 & $\begin{array}{c}124.50 \\
(738.40)\end{array}$ & $\begin{array}{r}126.45 \\
(738.70)\end{array}$ & $\begin{array}{r}150.24 \\
(719.70)\end{array}$ & $\begin{array}{r}152.20 \\
(720.95)\end{array}$ & $\begin{array}{c}6.93 \\
(65.44)\end{array}$ & $\begin{array}{c}8.91 \\
(66.01)\end{array}$ & $\begin{array}{c}319.60 \\
(919.84)\end{array}$ \\
\hline North Eastern & 2096 & $\begin{array}{l}-117.95 \\
(6083.80)\end{array}$ & $\begin{array}{c}-111.95 \\
(6023.41)\end{array}$ & $\begin{array}{l}67.00 \\
(371.11)\end{array}$ & $\begin{array}{l}72.23 \\
(379.92)\end{array}$ & $\begin{array}{c}5.43 \\
(46.75)\end{array}$ & $\begin{array}{l}10.66 \\
(102.00)\end{array}$ & $\begin{array}{l}405.71 \\
(5080.55)\end{array}$ \\
\hline South & 2214 & $\begin{array}{l}-4008.82 \\
(18156.70)\end{array}$ & $\begin{array}{l}-3964.47 \\
(17975)\end{array}$ & $\begin{array}{l}-3816.90 \\
(18152)\end{array}$ & $\begin{array}{l}-3772.54 \\
(17971)\end{array}$ & $\begin{array}{c}8.65 \\
(65.89)\end{array}$ & $\begin{array}{c}53.01 \\
(1816.60)\end{array}$ & $\begin{array}{l}426.70 \\
(740.14)\end{array}$ \\
\hline Centre & 4223 & $\begin{array}{c}196.00 \\
(846.70)\end{array}$ & $\begin{array}{r}201.00 \\
(851.90)\end{array}$ & $\begin{array}{r}213.30 \\
(878.40)\end{array}$ & $\begin{array}{r}218.30 \\
(883.90)\end{array}$ & $\begin{array}{c}-21.04 \\
(29.02)\end{array}$ & $\begin{array}{r}29.20 \\
(26.51)\end{array}$ & $\begin{array}{c}698.80 \\
(167.00)\end{array}$ \\
\hline Peru & 9285 & $\begin{array}{c}-888.17 \\
(84958)\end{array}$ & $\begin{array}{c}-876.25 \\
(84108)\end{array}$ & $\begin{array}{l}-777.53 \\
(84863)\end{array}$ & $\begin{array}{l}-765.61 \\
(84014)\end{array}$ & $\begin{array}{c}5.27 \\
(51.48)\end{array}$ & $\begin{array}{l}17.20 \\
(85.67)\end{array}$ & $\begin{array}{c}304.0 \\
(3027.50)\end{array}$ \\
\hline
\end{tabular}

Note: Numbers in parentheses are standard deviations. Money values are expressed in 1994 Soles, and are weighted using the weights provided by the World Bank and the Statistical Institute of Peru (INEI) 
Table 1.2 Average monthly per capita income quartiles and the two adjusted and unadjusted savings measures for 1994.

(Number of observations $=9282$ )

SAVE1/Income

SAVE2/Income

\begin{tabular}{lllllll}
\cline { 2 - 7 } Income quartile & Unadjusted & Adjusted & Difference & Unadjusted & Adjusted & Difference \\
\hline \hline Less than 645 & -0.202 & -0.190 & 0.012 & -0.155 & -0.142 & 0.013 \\
Between 645 and 1112 & 0.103 & 0.112 & 0.009 & 0.143 & 0.152 & 0.010 \\
Between 1112 and 4954 & 0.264 & 0.271 & 0.007 & 0.298 & 0.305 & 0.007 \\
Greater than 4954 & 0.402 & 0.408 & 0.006 & 0.428 & 0.434 & 0.007 \\
\hline \hline
\end{tabular}

Note: All income values are in 1994 Soles. 
Table 1.3(a) Reduced-form equations of income and savings estimates with downstream run-off consideration.

(Number of observations $=3622$ )

\begin{tabular}{|c|c|c|c|c|}
\hline \multirow[b]{2}{*}{ Variables } & \multirow{2}{*}{$\begin{array}{l}\text { Income } \\
\text { Estimate }(\mathrm{t})\end{array}$} & \multirow{2}{*}{$\begin{array}{l}\text { SAVE1 } \\
\text { Estimate }(t)\end{array}$} & \multirow{2}{*}{$\frac{\text { SAVE2 }}{\text { Estimate }(t)}$} & \multirow{2}{*}{$\frac{\text { SAVE3 }}{\text { Estimate }(t)}$} \\
\hline & & & & \\
\hline Intercept & $706.673(5.26)$ & $171.89(1.95)$ & $182.865(2.06)$ & $185.934(1.93)$ \\
\hline \multicolumn{5}{|c|}{ Regional locational adavantage dummies: } \\
\hline $\begin{array}{l}\text { yr } 1985 \\
\text { yr } 1994 \\
\text { yr } 1991\end{array}$ & $\begin{array}{l}205.902(2.03) \\
322.121(4.90) \\
-63.064(0.44)\end{array}$ & $\begin{array}{l}-29.13(0.44) \\
-13.852(1.12) \\
-75.583(0.81)\end{array}$ & $\begin{array}{l}-10.257(0.15) \\
-9.335(0.78) \\
-72.527(0.77)\end{array}$ & $\begin{array}{l}92.434(1.27) \\
14.554(2.97) \\
-53.976(0.53)\end{array}$ \\
\hline \multicolumn{5}{|c|}{ Rainfall Variables: } \\
\hline $\begin{array}{l}\text { Rlr } \\
\text { Rlrsq }\end{array}$ & $\begin{array}{l}14.087(3.91) \\
0.052(2.86)\end{array}$ & $\begin{array}{l}-2.027(0.86) \\
-0.006(0.44)\end{array}$ & $\begin{array}{l}-2.080(0.87) \\
-0.005(0.41)\end{array}$ & $\begin{array}{l}-0.085(0.30) \\
-0.004(0.28)\end{array}$ \\
\hline $\begin{array}{l}\mathrm{R} 2 \mathrm{r} \\
\mathrm{R} 2 \mathrm{rsq}\end{array}$ & $\begin{array}{l}3.399(1.10) \\
0.086(5.70)\end{array}$ & $\begin{array}{ll}0.803 & (1.44) \\
0.025 & (2.54)\end{array}$ & $\begin{array}{l}0.798(2.39) \\
0.026(2.65)\end{array}$ & $\begin{array}{ll}2.209 & (1.12) \\
0.028 & (2.56)\end{array}$ \\
\hline $\begin{array}{l}\mathrm{R} 3 \mathrm{r} \\
\mathrm{R} 3 \mathrm{rsq}\end{array}$ & $\begin{array}{l}-8.896(2.39) \\
-0.052(3.97)\end{array}$ & $\begin{array}{l}-1.949(0.80) \\
-0.009(1.05)\end{array}$ & $\begin{array}{l}-2.017(0.82) \\
-0.009(1.10)\end{array}$ & $\begin{array}{l}-1.701(0.64) \\
-0.002(0.26)\end{array}$ \\
\hline $\begin{array}{l}\mathrm{R} 4 \mathrm{r} \\
\mathrm{R} 4 \mathrm{rsq}\end{array}$ & $\begin{array}{l}10.476(2.12) \\
-0.002(0.33)\end{array}$ & $\begin{array}{l}4.479(1.39) \\
-0.004(1.06)\end{array}$ & $\begin{array}{l}4.445(1.73) \\
-0.005(1.12)\end{array}$ & $\begin{array}{l}6.352(1.80) \\
-0.013(2.91)\end{array}$ \\
\hline \multicolumn{5}{|c|}{ Household Composition variables: } \\
\hline kids06 & $-22.440(2.01)$ & $-3.105(0.43)$ & $-2.044(0.28)$ & $-24.489(3.07)$ \\
\hline $\begin{array}{l}\operatorname{ma} 712 \\
\mathrm{fe} 712\end{array}$ & $\begin{array}{l}-18.831(0.94) \\
15.751(0.81)\end{array}$ & $\begin{array}{l}-27.032(2.06) \\
7.898(0.62)\end{array}$ & $\begin{array}{l}-26.468(2.00) \\
7.603(0.59)\end{array}$ & $\begin{array}{l}-13.654(0.95) \\
-13.807(0.99)\end{array}$ \\
\hline $\begin{array}{l}\text { mal318 } \\
\text { fe } 1318\end{array}$ & $\begin{array}{l}22.615(1.00) \\
49.149(2.31)\end{array}$ & $\begin{array}{l}-6.103(0.41) \\
11.635(0.84)\end{array}$ & $\begin{array}{c}-5.661(0.38) \\
13.504(2.96)\end{array}$ & $\begin{array}{l}8.923(0.55) \\
2.600(0.17)\end{array}$ \\
\hline $\begin{array}{l}\text { ma1864prim } \\
\text { ma1864sec } \\
\text { ma1864posec }\end{array}$ & $\begin{array}{l}-7.007(0.64) \\
98.780(7.57) \\
394.546(14.22)\end{array}$ & $\begin{array}{l}7.881(1.10) \\
31.210(3.66) \\
110.495(6.08)\end{array}$ & $\begin{array}{l}7.834(1.08) \\
34.142(3.97) \\
128.600(7.03)\end{array}$ & $\begin{array}{l}-14.834(1.89) \\
7.379(0.79) \\
58.458(2.94)\end{array}$ \\
\hline $\begin{array}{l}\text { fe } 1864 \text { prim } \\
\text { fe } 1864 \text { sec } \\
\text { fe } 1864 \text { posec }\end{array}$ & $\begin{array}{l}-5.295(0.34) \\
136.000(8.57) \\
472.964(15.30)\end{array}$ & $\begin{array}{l}11.933(1.18) \\
38.921(3.75) \\
142.324(7.04)\end{array}$ & $\begin{array}{l}11.348(1.12) \\
44.685(4.27) \\
158.304(7.77)\end{array}$ & $\begin{array}{l}-14.071(1.28) \\
28.355(2.50) \\
59.731(2.70)\end{array}$ \\
\hline $\begin{array}{l}\text { ma65 } \\
\text { fea65 }\end{array}$ & $\begin{array}{l}61.864(3.67) \\
0.833(0.04)\end{array}$ & $\begin{array}{l}13.762(1.25) \\
-3.291(0.21)\end{array}$ & $\begin{array}{c}13.990(1.26) \\
-5.047(0.32)\end{array}$ & $\begin{array}{l}10.106(0.84) \\
-3.146(0.19)\end{array}$ \\
\hline \multicolumn{5}{|c|}{ Landownership dummies: } \\
\hline $\begin{array}{l}\text { mtlnd } \\
\text { ownlnd }\end{array}$ & $\begin{array}{l}-90.754(1.27) \\
-118.332(0.40)\end{array}$ & $\begin{array}{l}-8.014(0.17) \\
-29.753(0.15)\end{array}$ & $\begin{array}{l}-12.270(0.26) \\
-37.396(0.19)\end{array}$ & $\begin{array}{l}20.287(0.40) \\
-68.507(0.32)\end{array}$ \\
\hline$R^{2}:$ & 0.2453 & 0.0518 & 0.0621 & 0.0308 \\
\hline $\begin{array}{l}\text { F tests: p-value } \\
\text { Test } 1 \\
\text { Test } 2\end{array}$ & $\begin{array}{l}0.0000 \\
0.3973\end{array}$ & $\begin{array}{l}0.0051 \\
0.9723\end{array}$ & $\begin{array}{l}0.0034 \\
0.9461\end{array}$ & $\begin{array}{l}0.0000 \\
0.8840\end{array}$ \\
\hline
\end{tabular}

Note: Test 1 , rainfall significantly affects both income and savings.

Test 2, land ownership is insignificant. 
Table 1.3(b) Reduced-form equations of income and savings estimates without downstream run-off consideration.

(Number of observations $=3622$ )

\begin{tabular}{|c|c|c|c|c|}
\hline \multicolumn{5}{|c|}{ Income } \\
\hline Variables & Estimate (t) & Estimate (t) & Estimate (t) & Estimate (t) \\
\hline Intercept & $300.38(2.09)$ & $215.09(2.28)$ & $235.85(2.66)$ & $188.60(1.82)$ \\
\hline \multicolumn{5}{|c|}{ Regional locational adavantage dummies: } \\
\hline $\begin{array}{l}\text { yr1985 } \\
\text { yr } 1994 \\
\text { yrl } 1991\end{array}$ & $\begin{array}{l}288.08(4.21) \\
310.55(11.21) \\
100.17(1.26)\end{array}$ & $\begin{array}{ll}-29.961 & (-0.67) \\
-1.475 & (-1.53) \\
-9.419 & (-0.18)\end{array}$ & $\begin{array}{ll}-11.842 & (-0.26) \\
-3.451 & (-1.03) \\
-4.983 & (-0.09)\end{array}$ & $\begin{array}{l}60.897(1.23) \\
45.451(4.66) \\
-49.538(-0.86)\end{array}$ \\
\hline \multicolumn{5}{|c|}{ Rainfall Variables: } \\
\hline $\begin{array}{l}\text { R1r } \\
\text { Rlrsq }\end{array}$ & $\begin{array}{l}-1.838(-0.26) \\
0.086(1.99)\end{array}$ & $\begin{array}{l}-3.895(-0.84) \\
-0.024(0.86)\end{array}$ & $\begin{array}{cc}-4.514 & (-0.97) \\
0.029 & (1.41)\end{array}$ & $\begin{array}{l}0.456(0.09) \\
0.005(0.36)\end{array}$ \\
\hline $\begin{array}{l}\mathrm{R} 2 \mathrm{r} \\
\mathrm{R} 2 \mathrm{rsq}\end{array}$ & $\begin{array}{l}-2.715(-6.21) \\
0.005(1.30)\end{array}$ & $\begin{array}{l}-0.655(-2.28) \\
-0.001(-0.58)\end{array}$ & $\begin{array}{ll}-0.637 & (-2.20) \\
-0.001 & (-0.38)\end{array}$ & $\begin{array}{cc}-0.148 & (-0.47) \\
0.001 & (0.34)\end{array}$ \\
\hline $\begin{array}{l}\mathrm{R} 3 \mathrm{r} \\
\mathrm{R} 3 \mathrm{rsq}\end{array}$ & $\begin{array}{l}-0.230(-0.17) \\
-0.002(-0.40)\end{array}$ & $\begin{array}{c}-0.477(-0.54) \\
0.006(2.13)\end{array}$ & $\begin{aligned}-0.483 & (-0.54) \\
0.006 & (2.07)\end{aligned}$ & $\begin{array}{l}-2.333(-2.39) \\
-0.008(-2.52)\end{array}$ \\
\hline $\begin{array}{l}\mathrm{R} 4 \mathrm{r} \\
\mathrm{R} 4 \mathrm{rsq}\end{array}$ & $\begin{array}{l}4.760(1.24) \\
-0.134(-1.88)\end{array}$ & $\begin{array}{c}6.217(2.46) \\
-0.122(-2.59)\end{array}$ & $\begin{array}{ll}6.210 & (2.44) \\
-0.130 & (-2.74)\end{array}$ & $\begin{array}{rr}9.627 & (3.47) \\
-0.187 & (3.62)\end{array}$ \\
\hline \multicolumn{5}{|c|}{ Household Composition variables: } \\
\hline kids06 & $-8.333(-0.74)$ & $-2.277(-0.31)$ & $-1.066(-0.14)$ & $-23.318(-2.88)$ \\
\hline $\begin{array}{l}\operatorname{ma} 712 \\
\mathrm{fe} 712\end{array}$ & $\begin{array}{l}-16.375(-0.82) \\
25.695(1.32)\end{array}$ & $\begin{array}{c}-26.900(-2.05) \\
8.376(0.66)\end{array}$ & $\begin{array}{l}-26.386(-1.99) \\
8.171(0.63)\end{array}$ & $\begin{array}{l}-13.726(-0.95) \\
-12.981(-0.93)\end{array}$ \\
\hline $\begin{array}{l}\text { mal318 } \\
\text { fe } 1318\end{array}$ & $\begin{array}{l}27.853(1.32) \\
51.779(2.45)\end{array}$ & $\begin{array}{l}-4.989(-0.34) \\
12.558(0.90)\end{array}$ & $\begin{array}{l}-4.484(-0.30) \\
14.741(2.03)\end{array}$ & $\begin{array}{ll}9.712 & (0.52) \\
3.286 & (0.37)\end{array}$ \\
\hline $\begin{array}{l}\text { mal 864prim } \\
\text { mal 864sec } \\
\text { mal 864posec }\end{array}$ & $\begin{array}{l}9.571(0.86) \\
98.058(7.55) \\
378.64(13.69)\end{array}$ & $\begin{array}{l}9.128(1.25) \\
31.353(3.86) \\
109.56(6.03)\end{array}$ & $\begin{array}{l}9.249(1.26) \\
34.319(3.99) \\
127.520(6.96)\end{array}$ & $\begin{array}{l}13.906(1.74) \\
6.389(0.68) \\
55.790(2.80)\end{array}$ \\
\hline $\begin{array}{l}\text { fe1864prim } \\
\text { fe } 1864 \text { sec } \\
\text { fe } 1864 \text { posec }\end{array}$ & $\begin{array}{l}7.817(0.51) \\
119.74(7.56) \\
472.96(15.05)\end{array}$ & $\begin{array}{l}13.549(1.34) \\
37.620(3.61) \\
138.65(6.86)\end{array}$ & $\begin{array}{l}13.128(1.28) \\
43.216(4.12) \\
154.94(7.60)\end{array}$ & $\begin{array}{l}-13.521(-1.22) \\
25.598(2.24) \\
60.781(2.74)\end{array}$ \\
\hline $\begin{array}{l}\operatorname{ma} 65 \\
\text { fea65 }\end{array}$ & $\begin{array}{l}71.926(4.28) \\
7.947(0.34)\end{array}$ & $\begin{array}{l}14.528(1.32) \\
-3.781(-0.24)\end{array}$ & $\begin{array}{l}14.912(1.34) \\
-5.433(-0.35)\end{array}$ & $\begin{array}{l}10.573(0.87) \\
-4.171(-0.25)\end{array}$ \\
\hline \multicolumn{5}{|c|}{ Landownership dummies: } \\
\hline $\begin{array}{l}\text { rntlnd } \\
\text { ownlnd }\end{array}$ & $\begin{array}{l}-77.016(-1.09) \\
-331.13(-1.44)\end{array}$ & $\begin{array}{l}-10.302(0.21) \\
-9.782 \quad(-0.06)\end{array}$ & $\begin{array}{cc}-14.935 & (-0.32) \\
8.466 & (0.06)\end{array}$ & $\begin{array}{ll}19.290 & (0.38) \\
-33.374 & (-0.20)\end{array}$ \\
\hline$R^{2}:$ & 0.2536 & 0.0518 & 0.0621 & 0.0308 \\
\hline $\begin{array}{l}\text { F tests: p-value } \\
\text { Test } 1 \\
\text { Test } 2\end{array}$ & $\begin{array}{l}0.0000 \\
0.2653\end{array}$ & $\begin{array}{l}0.0166 \\
0.7525\end{array}$ & $\begin{array}{l}0.0023 \\
0.8617\end{array}$ & $\begin{array}{l}0.0001 \\
0.8840\end{array}$ \\
\hline
\end{tabular}

Note: Test 1 , rainfall significantly affects both income and savings.

Test 2, land ownership is insignificant. 
Table 1.4(a) Estimates of savings equation with downstream run-off consideration (Number of observations $=3622$ )

\begin{tabular}{|c|c|c|c|}
\hline \multirow[b]{2}{*}{ Variable } & \multicolumn{2}{|c|}{ SAVE1 SAVE2 } & SAVE3 \\
\hline & Estimates (s.e.) & Estimates (s.e.) E & Estimates (s.e.) \\
\hline$Y^{P}$ & $0.2670(0.0288)^{*}$ & $0.3075(0.0256)^{*}$ & $0.1936(0.0276)^{*}$ \\
\hline$\hat{Y^{T}}$ & $0.8461(0.0828)^{*}$ & $0.8838(0.07673)^{*}$ & $0.4089(0.1045)^{*}$ \\
\hline$\hat{\varepsilon}$ & $0.4878(0.0437)^{*}$ & $0.5116(0.0403)^{*}$ & $0.2815(0.0580)^{*}$ \\
\hline$W=$ Life-cy & tages of the househ & hold: & \\
\hline kids06 & $2.0766(3.8531)$ & $3.9847(3.7861)$ & $-17.0424(5.2686)^{* *}$ \\
\hline kids712 & $-8.1268(5.4108)$ & $-8.0672(5.2056)$ & $-11.7159(8.2098)$ \\
\hline kids 1317 & $-6.7255(6.1142)$ & $-7.1028(5.9046)$ & $-2.2370(8.4614)$ \\
\hline adult1864 & $7.9163(3.2883)^{* *}$ & $7.5627(3.1917)^{* *}$ & $-13.6327(4.4678)^{* *}$ \\
\hline above65 & $-2.8427(6.8212)$ & $-5.3041(6.8742)$ & $-7.1142(6.1660)$ \\
\hline
\end{tabular}

VAR $=$ Variability of regional rainfall:

stdR1 $2.6184(0.6047)^{* *} 2.6042(0.5719)^{* *}-0.8421(0.9257)$

stdR2 $\quad-4.0992(0.8484)^{* *}-4.3081(0.8796)^{* *}-1.4423(1.4158)$

stdR3 $4.0116(1.0752)^{* *} 4.3087(1.1048)^{* *} 1.9745(1.8784)$

$\begin{array}{llll}\text { stdR4 } & -0.5867(0.6984) & -0.5220(0.6432) & 0.8890(1.0078)\end{array}$

t - tests:

$\begin{array}{llll}\text { Test } 1 & 15.38 & 16.05 & 3.80\end{array}$

$\begin{array}{llll}\text { Test } 2 & 4.46 & 3.88 & 11.36\end{array}$

Note: ${ }^{*}$ Significant at the $2 \%$ significance level. ${ }^{* *}$ Significant at the $5 \%$ level.

Test $1, \alpha_{2}=1$. Test $2, \alpha_{1}=\alpha_{2}$. 
Table 1.4(b) Estimates of savings equation without downstream run-off consideration.

(Number of observations $=3622$ )

SAVE1 SAVE2 SAVE3

$\begin{array}{llll}\text { Variable } & \text { Estimates (s.e.) } & \text { Estimates (s.e.) } & \text { Estimates (s.e.) } \\ \hat{Y^{P}} & 0.2536(0.0173)^{*} & 0.2933(0.0165)^{*} 0.1765(0.0258)^{*} \\ \hat{Y^{T}} & 0.6429(0.0279)^{*} 0.8728(0.0266)^{*} 0.3915(0.0416)^{*} \\ \hat{\varepsilon} & 0.4798(0.0073)^{*} 0.5033(0.0070)^{*} 0.2786(0.0109)^{*} \\ \text { W }=\text { Life-cycle stages of the household: } \\ \text { kids06 } & 4.5558(4.8507) & 6.5499(4.6340) & -15.7242(7.2423) \\ \text { kids712 } & -5.859(5.9721) & -5.7107(5.7054) & -10.6534(8.9167) \\ \text { kids1317 } & -5.2675(6.6483) & -5.5475(6.3514) & -1.2032(9.9264) \\ \text { adult1864 } & 9.9027(3.4643)^{* *} 9.5965(3.3096)^{* *} & -11.4864(5.1725) \\ \text { above65 } & -0.4255(6.1659) & -2.9249(5.8905) & -4.6456(9.2060)\end{array}$

VAR = Variability of regional rainfall:

stdR1 $2.6028(0.7472)^{* *} 2.3728(0.7138)^{* *}-0.4563(1.1156)$

$\begin{array}{llll}\text { stdR2 } & -1.4460(0.9792) & -1.4712(0.8796) & -0.7007(1.4621)\end{array}$

$\begin{array}{llll}\mathrm{stdR} 3 & 0.0171(1.1964) & 0.1420(1.1429) & 0.5561 \\ (0.0863)^{* *}\end{array}$

$\begin{array}{lllll}\text { stdR4 } & 0.7237(0.5582) & 0.8661 & (0.5332) & 1.3056(0.0334)^{* *}\end{array}$

$\mathrm{t}$ - tests:

\begin{tabular}{llll} 
Test 1 & 12.41 & 12.66 & 2.86 \\
Test 2 & 5.45 & 4.78 & 12.03 \\
\hline
\end{tabular}

Note: * Significant at the $2 \%$ significance level. ${ }^{* *}$ Significant at the $5 \%$ level.

Test $1, \alpha_{2}=1$. Test $2, \alpha_{1}=\alpha_{2}$. 
Table 1.5 Estimates of savings when transitory income shock is defined as dummy variable

(Number of observations $=3622$ )

\begin{tabular}{|c|c|c|c|}
\hline \multirow[b]{2}{*}{ Variable } & SAVE1 & \multicolumn{2}{|c|}{ SAVE2 SAVE3 } \\
\hline & Estimates (s.e.) & Estimates (s.e.) & stimates (s.e.) \\
\hline \multicolumn{4}{|l|}{$n$} \\
\hline$Y^{P}$ & $0.2792(0.0231)^{*}$ & $0.3206(0.0852) * 0.1$ & $.1982(0.0275)^{*}$ \\
\hline$D_{n p}^{T}$ & $28.551(3.3992)^{*} 3$ & $30.142(3.3054) * 12$ & $.711(2.9642)^{*}$ \\
\hline$\wedge$ & & & \\
\hline $\mathcal{E}$ & $0.4502(0.0414)^{*}$ & $0.4728(0.0399) * 0$ & $.2619(0.0508)^{*}$ \\
\hline \multicolumn{4}{|c|}{ W $=$ Life-cycle stages of the household: } \\
\hline kids06 & $8.6893(4.2256)^{* *}$ & $10.826(4.0474)^{* *}-1$ & $13.6219(5.7564)^{* *}$ \\
\hline kids712 & $-1.8130(6.0948)$ & $-1.5056(5.9563)$ & $8.5494(4.3606)$ \\
\hline kids 1317 & $-7.8462(6.6949)$ & $-1.5056(6.7317)$ & $2.5686(8.7194)$ \\
\hline adult1864 & $8.0317(3.5523)^{* *}$ & $7.6134(3.2469)^{* *}-1$ & $13.3391(4.6200)^{* *}$ \\
\hline above 65 & $-2.4550(7.1671)$ & $7.6134(7.1054)$ & $6.5564(6.3362)$ \\
\hline \multicolumn{4}{|c|}{ VAR = Variability of regional rainfall: } \\
\hline stdR1 & $1.6601(0.6322)^{* *}$ & $1.6214(6.3631)$ & $-1.3669(1.0981)$ \\
\hline stdR2 & $-4.3420(0.9375)^{* *}$ & * $-4.6212(0.8889)^{* *}$ & $-1.3570(1.2084)$ \\
\hline stdR3 & $3.6247(1.1930)^{* *}$ & $3.9836(1.1168)^{* *}$ & $1.5183(1.5592)$ \\
\hline stdR4 & $-1.3988(0.6813)$ & $-1.4121(0.6721)$ & $0.6389(1.1335)$ \\
\hline
\end{tabular}

Note: $D_{n p}^{T}$ is a dummy variable where it is one if transitory income is positive and zero otherwise.

* Significant at the $2 \%$ significance level. ** Significant at the $5 \%$ level. 
Table 1.6 Estimates of savings when transitory income is defined as positive and negative shocks.

(Number of observations $=3622$ )

\begin{tabular}{|c|c|c|c|}
\hline \multirow[b]{2}{*}{ Variable } & SAVE1 & SAVE2 & SAVE3 \\
\hline & Estimates (s.e.) & Estimates (s.e.) & Estimates (s.e.) \\
\hline$\hat{Y^{P}}$ & $0.2696(0.0289)^{*}$ & $0.3101(0.0254)^{*}$ & * $0.1944(0.0280)^{*}$ \\
\hline$\hat{Y_{n e g}^{T}}$ & $0.9413(0.1215)^{*}$ & $0.9812(0.1167)^{*}$ & $0.4369(0.1534)^{*}$ \\
\hline$\hat{Y_{p o s}^{T}}$ & $0.7815(0.0786)^{*}$ & $0.8178(0.0716)^{*} 0$ & $0.3899(0.0976)^{*}$ \\
\hline$\hat{\varepsilon}$ & $0.4879(0.0437)^{*}$ & ${ }^{*} 0.5117(0.0392)^{*}$ & ${ }^{*} 0.2815(0.0575)^{*}$ \\
\hline W $=$ Life $-\mathbf{C}$ & stages of the housel & hold: & \\
\hline kids06 & $2.1872(3.8698)$ & $4.0977(3.6623)$ & $-17.0098(5.2863)^{* *}$ \\
\hline kids712 & $-8.0939(5.4120)$ & $-8.0336(5.1563)$ & $-11.7062(8.0852)$ \\
\hline kids 1317 & $-6.8135(6.0836)$ & $-7.1929(6.0411)$ & $-2.2629(8.3230)$ \\
\hline adult 1864 & $7.4838(3.2616)^{*}$ & * $7.1205(3.1108)^{*}$ & $* *-13.7600(4.4529)^{* *}$ \\
\hline above 65 & $-3.3177(6.8527)$ & $-5.7898(7.1863)$ & $-7.2540(6.2219)$ \\
\hline
\end{tabular}

VAR = Variability of regional rainfall:

stdR1 $2.7221(0.6034)^{*} 2.7102(0.5786)^{*}-0.8115(0.9111)$

$\begin{array}{lllll}\text { stdR2 } & -4.2107(0.8408) & -4.4222(0.8730) & -1.4751(1.4262)\end{array}$

stdR3 $\quad 4.2357(1.0690)^{* *} 4.5379(1.0936)^{* *} 2.0405(1.9447)$

$\begin{array}{lllll}\text { stdR4 } & -0.5186(0.7021) & -0.4524 & (0.6448) & 0.9088(1.0365)\end{array}$

Note: $Y_{n e g}^{T}=Y^{T}$ if $Y^{T}$ is less than or equal to zero and $Y_{p o s}^{T}=Y^{T}$ if $Y^{T}$ is greater than zero.

* Significant at the $2 \%$ significance level. ${ }^{* *}$ Significant at the $5 \%$ level. 
Appendix 1A Descriptive statistics of household variables

(Number of Households $=3622$ )

\begin{tabular}{lll}
\hline Variable & Mean & S.D. \\
\hline Tot Income & 552.04 & 475.11 \\
SAVE1 & 166.35 & 612.83 \\
SAVE2 & 199.49 & 620.82 \\
SAVE3 & 187.84 & 662.87
\end{tabular}

Regional Fixed Effects:

$\begin{array}{ll}\text { yr1985 } & 0.20 \\ \text { yr1991 } & 0.35 \\ \text { yr1994 } & 0.15\end{array}$

Region-Specific Rainfall Variables:

$\begin{array}{lll}\text { R1r } & 49.70 & 30.58 \\ \text { R1rsq } & 6948.71 & 7052.43 \\ \text { R2r } & -19.18 & 120.86 \\ \text { R2rsq } & 7424.29 & 6714.64 \\ \text { R3r } & -24.63 & 92.83 \\ \text { R3rsq } & 9221.06 & 8114.09 \\ \text { R4r } & -3.82 & 25.04 \\ \text { R4rsq } & 9557.53 & 9171.90 \\ \text { stdR1r } & 97.61 & 22.86 \\ \text { stdR2r } & 190.74 & 51.78 \\ \text { stdR3r } & 130.16 & 40.42 \\ \text { stdR4r } & 30.92 & 17.69\end{array}$

Land Ownership Variables:

$\begin{array}{ll}\text { milnd } & 0.03 \\ \text { ownlnd } & 0.87 \\ \text { both } & 0.16\end{array}$

Life-Cycle Stages of Household Composition:

kids06 1.07

kids712 $\quad 0.84$

kids $1317 \quad 0.66$

mal864 $\quad 1.92$

fe1864 1.57

ma65 0.30

fea65 0.20

Adult education levels:

ma1864prim $\quad 0.87$

mal864sec $\quad 0.84$

ma1864posec $\quad 0.21$

fe1864prim $\quad 0.76$

fe1864sec $\quad 0.66$

fel 1864 posec $\quad 0.15$

Note: All money values are in 1994 Nuevos Soles, hence the 1985/86 Intis was converted into 1994 Nuevo Sol using some adjustment factors, where one Nuevo Sol equals to 1000 Intis in 1991. 
Appendix 1B Descriptive statistics of rainfall across regions or rainfall stations $($ Number of Stations $=$ number of regions $=18)$

\begin{tabular}{lllll}
\hline Variable & Mean & S.D. & Min. & Max. \\
\hline \hline mnR1 & 212.64 & 35.51 & 173.42 & 253.89 \\
mnR2 & 453.15 & 68.96 & 262.07 & 372.76 \\
mnR3 & 322.28 & 52.52 & 259.70 & 382.97 \\
mnR4 & 78.55 & 13.71 & 64.00 & 376.73 \\
stdR1 & 132.03 & 7.44 & 121.53 & 141.81 \\
stdR2 & 266.30 & 7.92 & 255.08 & 274.91 \\
stdR3 & 188.96 & 5.08 & 181.60 & 193.97 \\
stdR4 & 48.82 & 2.27 & 45.27 & 51.45 \\
\hline \hline
\end{tabular}

Note: All rainfall measures are converted from inches to millimetres. 


\section{Appendix 1C Descriptions of variables used for the empirical analysis}

\begin{tabular}{|c|c|}
\hline Rjrt & The average rainfall of region $r$ in season $j$ of year $t$. \\
\hline Rrj & The average rainfall of region $r$ in season $j$ for the past twenty-eight years. \\
\hline R1 & The average rainfall in the first season, from January to March of the twenty-eight years. \\
\hline $\mathbf{R 2}$ & The same as above in the second season, for the months from April to June. \\
\hline $\mathbf{R 3}$ & The same as above in the third season, for the months from July to September. \\
\hline $\mathbf{R 4}$ & $\begin{array}{l}\text { The same as above in the last season of the year, for the months from October to } \\
\text { December. }\end{array}$ \\
\hline stdRjr & The standard deviation of average rainfall in each season for the twenty-eight years. \\
\hline $\mathbf{m n R j r}$ & The mean of the average rainfall in a given season for the twenty-eight years. \\
\hline $\mathbf{R} 1 \mathbf{r}$ & The deviation of R 1 from its historical mean in 1985/86 and 1994. \\
\hline $\mathbf{R} \mathbf{2} \mathbf{r}$ & The deviation of R2from its historical mean during the survey years. \\
\hline $\mathbf{R} 3 \mathbf{r}$ & The deviation of R3from its historical mean during the survey years. \\
\hline $\mathbf{R 4} \mathbf{r}$ & The deviation of $\mathrm{R} 4$ from its historical mean during the survey years. \\
\hline Rjrsq & The square of the deviation of seasonal rainfall from its historical mean. \\
\hline AvgSAVEi & The average monthly saving as defined by SAVEi. \\
\hline AdjSAVEi & Inflation adjusted saving as defined by SAVEi. \\
\hline kids06 & Number of children under the age of six. \\
\hline kids712 & Number of children between the ages of seven and twelve inclusive. \\
\hline kids1317 & Number of children between the ages of thirteen and seventeen inclusive. \\
\hline adult1864 & Number of adults between eighteen and sixty four inclusive. \\
\hline above65 & Number of people in the household who are sixty-five and above. \\
\hline mal1864prim & Number of male in this age group with a primary school education. \\
\hline mal1864sec & Number of male in this age group with a secondary school education. \\
\hline
\end{tabular}

(Continued) 
mal1864posec Number of male in this age group with a post-secondary school education.

rntind Number of farmers who rented land in the past twelve months.

ownInd Number of farmers who have their own land.

fea65 Number of female sixty-five and above.

ma65 Number of male sixty-five and above.

yr1985 Variable that captures locational and seasonal advantage or disadvantage in a given region during the 1985/86 surveys. Variables yr1991 and yr1994 have the same definition for their respective years.

WMO \# The World Meteorological Organization identification number.

PLSS Peruvian Living Standards Survey data. 
Appendix 1D Identification of regions, rainfall stations and zones for downstream run-off considerations

\begin{tabular}{lllll}
\hline Station/Region & Name & Zone & Run-off from Region & WMO \# \\
\hline \hline 1 & & 1 & None & 84377 \\
2 & Iquitos & 1 & None & 84425 \\
3 & Yurimaguas & 1 & 2 & 84435 \\
4 & Moyobamba & 1 & 2,3 & 84455 \\
5 & Terapoto & 2 & None & 84444 \\
6 & Chachapoyas & 2 & None & 84401 \\
7 & Puira & 2 & 6 & 84452 \\
8 & Chiclayo & 2 & 7 & 84501 \\
9 & Trujillo & 3 & 8 & 84531 \\
10 & Chimbote & 3 & None & 84564 \\
11 & Huanuco & 3 & None & 84628 \\
12 & Lima-Callao & 3 & None & 84658 \\
13 & Puerto Maldonado & 3 & 12 & 84691 \\
14 & Pisco & 4 & None & 84686 \\
15 & Cusco & 4 & 14 & 84701 \\
16 & San Juan De Marcona & 4 & 15 & 84745 \\
17 & Juliaca & 4 & 14,15 & 84752 \\
18 & Arequipa & 4 & 16,17 & 84782 \\
\hline \hline
\end{tabular}

Note: Zone 1 is the northwestern geographic area consisting regions 1 to 4 ; Zone 2 is the northeastern geographic area consisting regions 5 to 8; Zone 3 is the Central geographic area consisting regions 9 to 13; and Zone 4 is the Southern geographic area consisting regions 14 to 18 . 


\section{Appendix 1E Downstream run-off calculations}

For some downstream stations, especially those in the coastal area, regional rainfall values were increased to account for a downstream runoff consideration. For example, if $R_{i r}$ is the amount of rain recorded in station $r$ in season $\mathrm{i}$, and $\mathrm{k}$ is a station or region directly down to station $\mathrm{r}$, then the amount of rainfall in station $\mathrm{k}$ in season $\mathrm{i}$ is calculated as:

$$
R_{i k r}=0.75 R_{i r}+R_{i k}
$$

We assume $25 \%$ of the rain in region $\mathrm{r}$ has been converted into ground water or evaporated. Note also that station $\mathrm{k}$ could also be an upstream to yet another downstream station, say $\mathrm{j}$. In this case the amount of rainfall in station $\mathrm{j}$ in the same season is calculated as:

$$
R_{i j k}=0.75 R_{i k r}+R_{i j}
$$

Regions or stations affected by this are:

\section{Upstream donors}

Yurimaguas

Moyabamba

Puira

Chiclayo

Truijillo

Puerto Maldonado

Cusco

San Juan

Juliaca

Arequipa

\section{Downstream receivers}

Moyobamba

Tarapoto*

Chiclayo

Truijillo

Chimbote

Pisco

San Juan

Juliaca

Arequipa*

Tacna*

Note: * Runoff from two or more different stations. 


\section{Chapter 2}

\section{Weather variability, income shocks \\ and labour supply response of rural households in Peru}

\section{Introduction}

In most smoothing studies economists usually tend to examine saving or consumption behaviours of households while treating other household choices as fixed. If we consider saving and dissaving as the only consumption smoothing mechanism that is available to the household, assuming all other things to be constant, we may ignore the availability of other equally important measures that a household can take to achieve the same or even better result. The other problem in this is that households may not have any savings to use in bad times or further yet may be unable to borrow funds. Therefore, in this paper we will examine whether those households who take secondary or extra jobs do it for consumption smoothing purposes. In other words, we need to see if taking secondary or extra working hours is a labour supply mechanism used to reduce fluctuations in expenditure in response to income loss.

For this we will consider Kochar (1999) and follow Cameron and Worswick (2003). Both studies examined the household labour supply responses to income loss caused by crop 
loss. Kochar (1999) used the longitudinal data collected by the International Crop Research Institute of the Semi-arid Tropics (ICRISAT) for farm households in central India. Cameron and Worswick (2003) used the Indonesian Family Life Survey (IFLS) data. In particular, Cameron and Worswick (2003) examined if Indonesian households use labour supply measures to smooth consumption in response to crop-loss using a large cross-section data set taken from the 1993 IFLS data containing self-reported information on (1) crop loss and (2) household responses to crop loss. Unfortunately, the Peru Living Standards Survey (PLSS) data used in our analysis do not have a specific question on croploss or even income-loss, but it has information on whether the household members took a secondary-job or an extra-job during the survey year. We also have information on the number of hours spent on a secondary-job or on an extra-job. These include hours spent on other farms or in other wage-employment outside of the family owned or rented farm.

Kochar (1999) also devises a measure that exploits the information contained in the farmers cropping choices at the start of the season to estimate household expectations of weather in the season to come. To utilize as an instrument and to consistently estimate the effect of crop income shocks and to provide a check on the robustness of the results, Kochar (1999) used a record of any crop failure reported (in the ICRISAT) by the farmers in any given season.

The strength of our approach to this end is that we used regional specific variables, regional rainfall in this case, to proxy the transitory income shock. Where, time-series 
information on regional rainfall combined with the 1985/86 and 1994 PLSS crosssectional data on household income are used to obtain the estimates of the permanent and the transitory household income. We believe the actual record, as opposed to self-reported weather variability or crop loss, will give us more accurate information on the transitory income shock due to crop loss. Our study also contributes to this literature by shedding light on the role of taking working hours as a possible labour supply response to income loss.

This chapter is organized in the following way. Section II discusses the theoretical concept behind labour supply responses of households to absorb negative income shocks. In particular, reasons are provided for considering household members' extra hours of work as a mechanism for labour supply response to shocks. Section III and IV develops an empirical model of savings and hours of work in the presence of rainfall fluctuations and discusses methods of estimation. The data employed and the empirical results are explained in section V. Policy implications and concluding remarks will be given in section VI. 


\section{Theoretical background}

There are a variety of dimensions of labour supply. The static income-leisure choice framework under the assumption that leisure is a normal good, predicts that an increase in nonlabour income (i.e., a positive transitory income shock in our case) will have an income effect increasing the demand for leisure and reducing the hours of work. In addition, it is more beneficial, for example, for household members to specialize to some extent in the work that needs to be done both in the market and in the household. Often, in the household one may be responsible for preparing meal, shopping, home maintenance or child rearing. If the adults in the household all work either for pay or in the farm, some of them may be more available for extra-job or secondary-job to offset the loss in the case of a crop loss.

We should also keep in mind that cultural factors side by side with economic factors discussed above play an important role in the household decision-making process. In fact, the choice of who handles what kind of household duty is influenced by relative household productivity and/or market productivity does not imply that customs are unimportant in shaping preferences or in limiting choices concerning the household. The household productivity theory and participation is thoroughly discussed in Benjamin, Gunderson and Riddell (2002).

Household members may vary the hours they supply to the labour market over their lives. Moreover, households may use a saving and dissaving mechanism to smooth consumption 
as discussed in our first chapter or they may increase their hours of work by taking a wage-job or working on other farms again to smooth consumption and absorb the shock. The extent of the household labour supply or increased hours of work in response to crop loss will be examined and analyzed using appropriate data and empirical methods. 


\section{Derivation of the Model}

There are two important questions that must be answered by our model:

(i) Do households take on secondary wage employment and increase the overall household members' working hours?

(ii) Do households take on extra work outside their own farm (or they shift their working place) because of income-loss due to variability in rainfall, but do not necessarily increase total working hours?

In order to answer these questions we use hours of work information in own-farm and/or in wage-employment. The World Bank Peru Living Standards Survey (PLSS) data provides information on household members' current bi-weekly and annual hours in every incomegenerating activity in the survey year.

Rural households are assumed to choose hours of work on own farm and hours work on wage-employment so as to maximize the expected value of discounted lifetime family utility. There is a trade-off of work and leisure across time. Under "normal" or "average" circumstances, households will have chosen optimal hours of work to put in each month or year. The household then re-optimizes inter-temporally where possibly leading to more current and less future work to smooth utility levels across time periods. The standard dynamic, labour supply model is extended to allow for a separate use of own-farm and wage-employment, and in both cases households could have worked extra hours to smooth 
current as well as future consumption. The appropriate lifetime utility function,

$$
U(t)+\frac{1}{1+\rho} E_{t}\left\{\sum_{\tau=t+1}^{T} \frac{U(\tau)}{(1+\rho)^{\tau-t-1}}\right\}
$$

is maximized subject to the saving constraint:

$$
\begin{aligned}
S(\tau) & =A(\tau)-A(\tau-1)(1+r(\tau)) \\
& =w(\tau) h_{w}(\tau)+F\left(h_{f}(\tau)\right)-p(\tau) c(\tau)
\end{aligned}
$$

Utility at time $\tau$ is a function of consumption $(\mathrm{c}(\tau))$ and family leisure time $(\mathrm{l}(\tau))$. Note that family leisure time, $1(\tau)=T(\tau)-h_{w}(\tau)-h_{f}(\tau) . \rho$ is the rate of time preference, $p(\tau)$ is the price of the composite commodity; $h_{w}(\tau)$ and $h_{f}(\tau)$ are respectively a household member's hours of work for wages and hours worked on own-farm in period $\tau ; w(\tau)$ is the wage rate, $F\left(h_{f}(\tau)\right)$ is a strictly concave household own-farm production function. $A(\tau)$ is a non-human wealth at the end of period $\tau$ and $A(\tau) \geq 0 ; r(\tau)$ is the interest rate at time $\tau$. The household can sell off assets, which it holds at the beginning of the period, but it cannot allow its end of period asset to drop below zero (Zeldes, 1989). The household own-farm production function is assumed to have the form:

$$
y(\tau)=F\left(h_{f}(\tau)\right)=e^{v(\tau)} f\left(h_{f}(\tau)\right)+u(\tau)
$$

Where $v(\tau)$ and $u(\tau)$ are mean zero random shocks to the household production.

The random shock $u(\tau)$ can be thought of as a shock to farm output that does not affect the marginal product of labour in farming that period. In contrast, $v(\tau)$ affects the value of time devoted to agriculture. To examine whether households substitute out working on own-farm into wage-employment or if they just take extra working hours available into the 
labour market, we have to differentiate between the two types of transitory shocks mentioned above.

Assuming interior solutions for consumption, wage-employment working hours, and ownfarm working hours, we have three necessary conditions from the above dynamic optimization problem:

$$
\begin{aligned}
& \frac{\partial U(\tau)}{\partial c(\tau)}=\lambda(\tau) \\
& \frac{\partial U(\tau)}{\partial l(\tau)}=\lambda(\tau) w(\tau) \\
& \frac{\partial U(\tau)}{\partial l(\tau)}=\lambda(\tau) e^{v(\tau)} \frac{\partial f}{\partial h_{f}}
\end{aligned}
$$

Where $\lambda(\tau)$ is the multiplier, which can be interpreted as the marginal utility of wealth at time $\tau$. We could introduce participation constraints for $h_{w}(\tau)$ and $h_{f}(\tau)$; however, for simplicity it is assumed that each farming household devotes some time to each activity. Extending the model to allow for participation constraints would not change the qualitative nature of the relationships examined in this section. The multiplier also has the following motion equation:

$$
\lambda(t)=\frac{1}{1+\rho} E_{t}\{\lambda(t+1)(1+r(t+1))\}+\gamma(t)
$$

Note that $\gamma(t)$ is the multiplier or the asset non-negativity constraint $(\mathrm{A}(\mathrm{t}) \geq 0)$ for period $t$. If the household is credit constrained in period $\mathrm{t}$, then $\gamma(t)>0$, and the household would like to lower its end of period asset, $A(t)$, below zero by borrowing against future earnings. 
On the other hand, if the household is not credit constrained, the expected present value of the increase in utility from another unit of wealth in period $t+1$, would be equal to the cost in terms of the decrease in utility in period $t$, that is:

$$
\frac{1}{1+\rho} E_{t}\{\lambda(t+1)(1+r(t+1))\}=\lambda(t)
$$

Although $u(\tau)$ does not enter directly into the first order conditions, it does have an effect on farm output by operating through the multiplier. A large negative $u(\tau)$ is a transitory income shock to income in period $\tau$. By consumption smoothing, the household will use assets to smooth its effect over future time period, meaning that there would only be a small positive effect on $\lambda(\tau)$ leading to a small negative effects on $c(\tau)$ and $l(\tau)$ due to the concavity of $\partial U(\tau) / \partial c(\tau)$ and $\partial U(\tau) / \partial l(\tau)$ implying small increases in $h_{w}(\tau)$ and $h_{f}(\tau)$. However, if sufficient assets are not available to offset the negative transitory income $(A(\tau)=0)$ then the magnitude of all these effects will be larger. The decrease in $c(\tau)$ will be large as will be the increase in both $h_{w}(\tau)$ and $h_{f}(\tau)$. Note, however, that the household's ability to increase its labour supply to either the own farm activity and/or the labour market activity, means that it can generate income to reduce the need for even greater reduction in current consumption $(c(\tau))$.

A positive or negative income shock due to rainfall variability acting through $v(\tau)$, however, may have a large impact on hours of own-farming and of wage-employment hours even in the absence of credit constraints $(A(\tau) \geq 0)$. Other things being the same, 
this may have the effect of reallocation of household's time away from the own-farm to wage-employment, making supplying more hours to wage-employment more attractive. 


\section{Estimation methods and strategy}

Assume that $U(\tau)$ is separable between $c(\tau)$ and the total hours of work, $H(\tau)=\mathrm{T}-l(\tau)$, therefore,

$$
\frac{\partial U(T-l(\tau))}{\partial l(\tau)}=\lambda(\tau) w(\tau)
$$

Taking logs of both sides:

$$
\ln \left[\frac{\partial U(T-l(\tau))}{\partial l(\tau)}\right]=\ln \lambda(\tau)+\ln w(\tau)
$$

The first order Taylor Series Approximation of the left hand side of equation (2.10), in terms of $T-l(\tau)=H(\tau)$, gives us an equation that would lead us to our estimable equation:

$$
\begin{aligned}
T-l(\tau) & =H(\tau) \\
& =\beta_{0}+\beta_{1} \ln w(\tau)+\beta_{2} \ln \lambda(\tau)+e_{H}(\tau)
\end{aligned}
$$

Where $e_{H}(\tau)$ is the random part of preferences over leisure.

Equation (2.11) is just an approximation. Furthermore, we do not observe $\lambda(\tau)$, but we know that $\lambda(\tau)$ increases when there is bad weather (negative shock), and decrease when there is good weather. For example, $\lambda(\tau)$ increases when $v(\tau)<0$ or $u(\tau)<0$, because the marginal utility of income must go up as lifetime income decreases. This effect will be larger in magnitude when the household is credit constrained $(A(\tau)=0)$. Also, $\lambda(\tau)$ decreases when $v(\tau)>0$ or $u(\tau)>0$, because the marginal utility of income must go 
down as lifetime income increases. It is, therefore, possible to put the transitory weather variables, $X^{T}$, and the permanent income variables, $X^{P}$, as proxies to the marginal utility of household income:

$$
H(\tau)=\delta_{0}+\delta_{1} \ln w(\tau)+\delta_{2}^{T} X^{T}(\tau)+\delta_{3}^{P} X^{P}(\tau)+\varepsilon_{H}(\tau)
$$

Where, $\varepsilon_{H}(\tau)$ includes $e_{H}(\tau)$ and the unexplained component of $\ln \lambda(\tau)$.

The wage rate $w(\tau)$ is also correlated to permanent household income and will be absorbed into the $X^{P}$ variable. In fact, we can proxy both the permanent and the transitory income variables by our estimates of the transitory and the permanent income $\hat{Y_{r r}^{T}}$ and $\hat{Y_{i r}^{P}}$. We will also add the household specific education-age vector, $W_{\text {irt }}$, into this estimable equation:

$$
H_{i r t}=\gamma_{0}+\gamma_{1} \hat{Y}_{i r t}^{P}+\gamma_{2} \hat{Y}_{r t}^{T}+\gamma_{3} W_{i r t}+\rho_{i r t}
$$

Where $H_{i r}$ is the total hours worked (same as the above vector representation). It is the sum of total hours spent on own-farm and hours spent on wage-employment. These include, but not limited to, the hours spent on self-employment, on farm, on extra work or works, on usual jobs and other wage paying jobs. Where $\mathrm{i}, \mathrm{r}$, and $\mathrm{t}$ represent household, region and time respectively. In general, all of these variables are defined as the difference between total time and leisure time for each household. The expected value of $\rho_{\text {irt }}$ is equal to zero.

To see the collective (as opposed to the estimated ones) effect and interactions of the 
permanent income variables on the estimated transitory income we will repeat the above procedure in the form of the following reduced form equation:

$$
H_{i r t}=\eta_{0}+\eta_{1} X_{i r t}^{P}+\eta_{2} \hat{Y_{r t}^{T}}+\eta_{3} W_{i r t}+\mu_{i r t}
$$

To calculate the estimates of the transitory and the permanent incomes we need to first estimate the reduced form of total income equation of Chapter 1:

$$
Y_{i r t}=Y_{i r t}^{P}+Y_{i r t}^{T}=\beta_{t}+\beta_{1} X_{i r t}^{P}+\beta_{2} X_{r t}^{T}+\varepsilon_{i r t}
$$

Where, $Y_{i r t}$ is the total income of household $\mathrm{i}$ in region $\mathrm{r}$ for the year $\mathrm{t} . X_{r}^{T}$ is a vector of variables that are correlated with transitory income, regional rainfall in this case and has exact definition as in Chapter 1 . However, $X_{i r}^{P}$ is slightly different. It is a vector of variables that could permanently affect income, such as land ownership, household composition by age (of those above 15), gender, and education level. Since the total household income is the sum of the permanent income, $Y_{i r t}^{P}$, and transitory income, $Y_{i r}^{T}$, it can now be estimated from the results of equation (2.14) using the following procedure:

$$
\begin{aligned}
& \hat{Y_{i r t}^{P}}=\hat{\beta_{0}}+\hat{\beta}_{1} X_{i r t}^{P} \\
& \hat{Y_{i r t}^{T}}=\hat{\beta}_{2} X_{r t}^{T}
\end{aligned}
$$

Next we can do the same kind of exercise using equation (2.6), the last equation of the first order necessary conditions. Taking logs of both sides:

$$
\ln \left[\frac{\partial U(T-l(\tau))}{\partial l(\tau)}\right]=\ln \lambda(\tau)+v(\tau)+\ln \left(\frac{\partial f}{\partial h_{f}}(\tau)\right)
$$

Note that the left hand side of this equation is the same as the left hand side of equation 
(2.10), therefore, we could write:

$$
\begin{aligned}
& \ln \lambda(\tau)+\ln w(\tau)=\ln \lambda(\tau)+v(\tau)+\ln \left(\frac{\partial f}{\partial h_{f}}(\tau)\right) \\
& \ln w(\tau)=\ln \left(\frac{\partial f}{\partial h_{f}}\right)+v(\tau)
\end{aligned}
$$

Again note that since $f\left(h_{f}(\tau)\right)$ is concave, the term $\ln \left(\frac{\partial f}{\partial h_{f}}\right)$ will be a function of $h_{f}(\tau)$. Therefore, taking the first order Taylor Series Approximation of equation (2.18) in $h_{f}(\tau)$, $\ln w(\tau)$, and $v(\tau):$

$$
h_{f}(\tau)=b_{0}+b_{1} \ln w(\tau)+v(\tau)
$$

We can estimate this equation since we have information on working hours on own farm. We can use the transitory weather variable, $X^{T}$, as a proxy for $v(\tau)$ and the permanent income variables, $X^{P}$ and $W_{i r t}$, are proxies to $\ln w(\tau)$ and get:

$$
h_{f}(\tau)=a_{0}+a_{1} X_{i r t}^{P}+a_{2} X_{r t}^{T}+a_{3} W_{i r t}+\varpi_{i r t}
$$

We can again replace the transitory rainfall variable, $X_{r t}^{T}$, with the estimated value of the transitory income, $\hat{Y}_{i r t}^{T}$, and, $X_{i r t}^{P}$, with the estimated value of the permanent income, $\hat{Y}_{i r t}^{P}$, using equation (2.15).

$$
h_{f}(\tau)=\alpha_{0}+\alpha_{1} \hat{Y_{i r t}^{P}}+\alpha_{2} \hat{Y_{r t}^{T}}+\alpha_{3} W_{i r t}+e_{i r t}
$$

$W_{i r t}$ has a different definition here in this chapter. It comprises labour participation of adult male and female household members (above age 15), and school enrollment of children 
male and female members (between six and 16). The expected value of the error term, $\boldsymbol{e}_{i r t}$, is equal to zero.

For the same reason as in equation (2.13b) we will estimate the following equation for own-farm and wage-employment hours:

$$
h_{f}(\tau)=\alpha_{0}+\alpha_{1} X_{i r t}^{P}+\alpha_{2} \hat{Y_{n}^{T}}+\alpha_{3} W_{i n t}+e_{i n}
$$

We follow the following two steps in estimating the above equations. We regress the total income on the vectors of the permanent and transitory income variables (equation (2.14)) and calculate the estimated value of the permanent income (equation (2.15)) and the estimated value of the transitory income (equation (2.16)). The second step is to examine the hours of work equation to see whether households increase their hours of work in response to income shock due to weather variability. We will estimate the two hours of work measures (total and extra) to see the extent to which households respond to income shocks. The hours of work equations are separately considered using the two equations we derived. Equation (2.13a) is used to see the total hours of work variation including the variations on total extra working hours. Where as equation $(2.20)$ is used to see the variation in own-farm as well as wage-employment working hours, including hours in usual-jobs and hours in temporary jobs. The two-stage and the bootstrap estimates of these equations have no differences. We report results from the later. The bootstrap estimates of results from equation (2.13b) and equation (2.20b) are reported in the Appendix. 


\section{Data and results}

The model presented above was estimated using data from two different sources. First, samples of rural Peruvian households whose living was based on land were selected from the $1985 / 86$ and the 1994 PLSS data of the World Bank. These cross-section data provide information on annual and weekly own-farm and outside own-farm working hours of all rural household members. There is also information on whether household members take on extra-jobs or secondary-jobs including how much time they spend working at those jobs per week and per year. Therefore, by assuming the eight-hour per day as a normal working day, we calculated the number of extra working hours per month per household for our empirical work. We used two separate estimates of extra work hours: extra hours spent on household members' primary jobs (usual jobs) as well as extra hours spent on secondary jobs (temporary jobs). The explanation on how these data were collected is covered in Chapter 1, however, more explanation on working hours variables is give in Appendix 2E. Second, we use a time-series data on regional rainfall collected by the United States National Oceanic and Atmospheric Administration (NOAA). We combined these two data to obtain the positive and negative transitory component of household income due to shocks in regional rainfall.

Table 2.1 presents the results from the estimation of the reduced form income equation. These results are very similar to the estimated results of table (1.3), column 1. However, the variables those define $X^{P}$ and $W_{i r t}$ are different in both cases. In chapter 1 , 
$X^{P}$ represents vectors of household specific variables that include land ownership, number of household members and characteristics including 13 groups of age, gender and education level. Whereas in this chapter it represents vectors of household specific characteristics that could permanently affect income, such as land ownership, 12 groups of household composition by age (of those above 15), gender, and education level. The lifecycle variable $W_{i r t}$, in Chapter 1 , consists of number of household members in five age groups (see table 1.4). However, in this chapter the life-cycle variables consist of adult labour participation and children school enrollment by age groups.

Table 2.2, 2.3 and 2.4 report the results, over the whole sample, of the total monthly hours of work spent by the household in a non-farm activity and the total hours of work farmers spent on their farm. Please refer to Appendix 2E for definitions and explanations of hours of work variables. In particular, table 2.3 records the results when the transitory variable is defined by a dummy variable, where it is one if the transitory income is negative and zero otherwise. In table 2.4 we separated the positive and negative transitory income shocks to see their effect on working hours. The results in this table indicate that the coefficient of the permanent income due to the increase in total hours of work in non-farm hours to be negative and statistically significant at the one-percent level. However, according to table 2.2 , when the transitory income is negative (when there is a negative shock), the total working hour declines, the on-farm working hours declines but the non-farm working hours increases only by $10 \%$ or less. This result is consistent to the findings when we used a dummy variable for the transitory income. Both results of table 2.3 and 2.4 show the 
coefficients due to the negative shock to be large but statistically insignificant. In table 2.3, as in table 2.2 the total working hours and the on-farm working hours declined due to the negative shock, but the non-farm working hours increased insignificantly. In table 2.4, when the negative and positive shocks are separated, when the shock is negative, both the total working hours and the non-farm working hours declined where as the farm working hours increased all insignificantly. In table 2.4 and in the case of the positive shock, there is no significant difference in both total hours of work and on-farm hours of work. However, there is a decrease in the non-farm working hours for both negative and positive shocks (more significant in the negative shock case) and this is consistent with the theory of credit constraint. In general, this result indicates that the income generated from the labour supply response ( be it on-farm or non-farm working hours) is an important part of household's reaction to income loss due to weather variability.

In table $2.5,2.6$ and 2.7 , the estimates of total extra hours on farm and non-farm working hours were reported. The basic results are very similar to that of the total working hour discussed above. However, one important distinction is that the coefficients for the transitory income on farm of the adult male labour participation is much more significant compared to the adult male on non-farm activities. In particular, both the 17 to 64 and above 65 age categories in these tables are more significant than the previous three tables combined. However, there is no much of a difference in the farm or the non-farm results for the total female variable. In both farm and non-farm activities the male or female 18-64 age group have a very significant role, when only extra total working hours is considered. 
The results given in table 2.4 and table 2.7 are better indicators of the extent to which farm households respond to income shocks. In table 2.4 , a one standard deviation decrease in transitory income will bring about a $7 \%$ and $4 \%$ decline in the total working hours and on-farm working hours respectively. It also causes a $25 \%$ increase in the non-farm working hours, which is significant. In table 2.7 , when total extra working hours is considered, a one standard deviation increase in the negative transitory income will cause a $2 \%$ increase in total extra working hours, a $2.5 \%$ increase in extra working hours on farm and a significant $25 \%$ increase in extra non-farm working hours. However, a one standard deviation increase in the positive transitory income will result in a $10 \%$ decline in total extra working hours, an insignificant increase in non-farm working hours and a significant $(22 \%)$ increase in on-farm working hours. 
The reported measures of household's labour supply response due to income loss, in the data, shows very little evidence of taking extra jobs or increasing working hours. Our findings also prove that it is not difficult to apply a model that proxies labour supply response to test the hypothesis that households are able to smooth consumption through increases in the working hours. In some rural Peruvian cases, however, we suspect households will cut expenses significantly to smooth consumption in the face of income loss due to weather variability rather than increasing working hours. On the other hand, there is enough evidence that indicates that income generated from increases in hours of work play an important role in smoothing consumption in case of income loss.

According to our findings in Chapter 1, some households may have also used the natural saving and dissaving mechanism to smooth consumption when faced with income loss due to unfavorable rainfall. Other households, had to re-allocate their labour from their permanent job (this could be, working on the family or rented farm) to the more productive extra or secondary job (non-farm activity).

Therefore, we believe due to the volatility of the rural labour market any policy concerning rural labour force should reflect the diverse problems faced by the household. These policies should also reflect working habits of the rural population. For instance, our result clearly shows that a large percentage of households do not take extra working hours or 
increase own or rented farm activity to absorb the transitory income shock due to weather variability, instead they choose to use other mechanisms. To say what this means to policy-makers is not the intention of this paper, but this is certainly something that should be considered when developing a working policy.

In all of our estimations we hoped to find enough evidence that the transitory income associated with the shock due to rainfall variability to cause households to shift working conditions or increase working hours, because these are important factors for households in allowing them to smooth consumption. However, households in Peru do not seem to increase total working hours even in the presence of these shocks instead they do use their savings as well as shift or reallocate their labor away from farm to a more productive or more income generating employment. 


\section{References}

Dwayne Benjamin, Morley Gunderson and W. Craig Riddell, Labour Economics: Theory, Evidence, and Policy in Canada. $5^{\text {th }}$ edition, McGraw-Hill Ryerson (2002)

Surjit S. Bhalla, "Measurement Errors and the Permanent Income Hypothesis: Evidence from Rural India," The American Economic Review, Vol. 69 No. 3, June 1979, 295-307

------, "The Role of Sources of Income and Investment Opportunities in Rural Savings," Journal of Development Economics, Vol. 5, 1978, 259-81

Olivier Jean Blanchard \& Stanley Fisher, Lectures on Macroeconomics, (The MIT Press, 1989)

Lisa A. Cameron \& Christopher Worswick, "The Labor Market as a Smoothing Device: Labor Supply Responses to Crop Loss," Review of Development Economics, Vol. 7 No. 2, 2003, 327-341

Angus Deaton, The Analysis of Household Surveys, A Microeconometric Approach to Development Policy, Published for the World Bank, The Johns Hopkins University Press, Baltimore and London, July 1997.

Irving Fisher, The Theory of Interest, (NY, Augustus Kelly, First ed. 1930 and the 1961 ed.)

Milton Friedman, A Theory of the Consumption Function, (Princeton University Press, 1957.)

Anjini Kochar, "Smoothing Consumption By smoothing Income: Hours-of-work Responses to Idiosyncratic Agricultural Shocks in Rural India," The Review of 
Economics and Statistics, February 1999, Vol. 81(1): 50-61

Simon Smith Kuznets, National Income: Summary of findings, National Bureau of Economic Research, inc., 1946.

Sonia Laszlo, "Self-Employment Earnings: an Empirical analysis of Non-Farm

Activities in Rural Peru," Journal of Development Studies, 2005, Vol. 41(7): 12471287

Thomas Mayer, Permanent Income, Wealth and Consumption, (Los Angeles, Berkeley 1972)

Franco Modigliani, "Fluctuations in the Savings-Income Ratio: A Problem in Economic Forecasting," Studies in Income and Wealth, Vol. 11 (NY, National Bureau of Economic Research, 1949)

-------, “The Life Cycle Hypothesis of Saving, The Demand for Wealth and The Supply of Capital," Social Research, Vol. 33, summer 1966, 160-217

--------, "The Life Cycle Hypothesis of saving and Inter country differences in the Saving Ratio," in W. Eltis, M. Scott and J. Wolfe (eds.) Induction, Growth and Trade, Essays in Honor of Sir Roy Harrod (Oxford, Clarendon Press, 1970) 197-225

Philip Musgrove, "Permanent Household Income and Consumption in Urban South America," American Economic Review, Vol. 69 No. 3, June 1979

Christina H. Paxson, "Using Weather Variability To Estimate the Response of Savings to Transitory Income in Thailand," American Economic Review, Vol. 82 No. 1, March 1992

Kenneth I. Wolpin, “A New Test of the Permanent Income Hypothesis: The Impact of 
Weather on the Income and Consumption of Farm Households in India," International Economic Review Vol. 23 No. 3, October 1982

The World Bank, Peru Living Standards Measurement Survey (PLSS) 1994, Basic Information, Poverty and Human Resources Division, August 1998.

United States Department of Commerce, Surface Hourly Abbreviated 6, 12 and 24-Hour Liquid Precipitation Report in Inches and Hundredths on Peruvian Sites, National Data Centers, National Oceanic and Atmospheric Administration (NOAA), National Environmental Satellite, Data and Information Service. 
Table 2.1 Estimates of the reduced-form income equation

(Number of observations $=3622$ )

\begin{tabular}{|c|c|c|}
\hline \multirow[b]{2}{*}{ Variable } & \multicolumn{2}{|c|}{ Income } \\
\hline & Estimate & (t-value) \\
\hline Intercept & -909.54 & $(-1.09)$ \\
\hline \multicolumn{3}{|c|}{ Rainfall Variables } \\
\hline R1r & -0.38 & $(-0.23)$ \\
\hline R1rsq & 0.11 & $(8.84)$ \\
\hline $\mathrm{R} 2 \mathrm{r}$ & 5.28 & (3.81) \\
\hline R2rsq & 0.81 & (17.18) \\
\hline R3r & 16.55 & $(9.61)$ \\
\hline R3rsq & -0.22 & $(-2.10)$ \\
\hline $\mathrm{R} 4 \mathrm{r}$ & 34.17 & $(6.43)$ \\
\hline R4rsq & 0.28 & (7.71) \\
\hline \multicolumn{3}{|c|}{ Household composition by age, gender and education level: } \\
\hline $\operatorname{mal} 417$ & 27.853 & $(1.32)$ \\
\hline fel417 & 51.779 & $(2.45)$ \\
\hline mal 864 & 89.45 & $(12.96)$ \\
\hline fel 1864 & 42.56 & $(3.25)$ \\
\hline mal 864prim & 9.571 & $(0.86)$ \\
\hline $\mathrm{mal} 864 \mathrm{sec}$ & 98.058 & $(7.55)$ \\
\hline mal 864posec & 378.64 & $(13.69)$ \\
\hline fe1864prim & 7.817 & $(0.51)$ \\
\hline fel $1864 \mathrm{sec}$ & 119.74 & $(7.56)$ \\
\hline fel 864 posec & 472.96 & $(15.05)$ \\
\hline ma65 & 71.926 & $(4.28)$ \\
\hline fea65 & 7.947 & $(0.34)$ \\
\hline \multicolumn{2}{|c|}{ Land ownership dummies: } & $(-1.00)$ \\
\hline ownlnd & -432.42 & $(-1.21)$ \\
\hline$R^{2}:$ & 0.2862 & \\
\hline \multicolumn{3}{|l|}{ F tests: } \\
\hline Test 1 & 0.0001 & \\
\hline Test 2 & 0.3245 & \\
\hline
\end{tabular}

Note: Test 1 , rainfall variables jointly and significantly affect income.Test 2 , land ownership variables are jointly insignificant. 
Table 2.2 Estimates when hour is total and transitory income is undivided. (Number of observations $=3622$ )

\begin{tabular}{|c|c|c|c|}
\hline \multirow[b]{2}{*}{ Variable } & Htot & Farm & Non-farm \\
\hline & Estimate (s.e.) & Estimate (s.e.) & Estimate (s.e) \\
\hline \multicolumn{4}{|l|}{$\wedge$} \\
\hline$Y^{P}$ & $0.5196(0.0481)$ & $-0.6372(0.0240)$ & $-0.1045(0.0397)$ \\
\hline \multicolumn{4}{|l|}{$\wedge$} \\
\hline$Y^{T}$ & $0.8539(0.0488)$ & $0.8018(0.0226)$ & $-0.0778(0.0404)$ \\
\hline \multicolumn{4}{|c|}{ Adult Labour Participation } \\
\hline $\operatorname{mal} 764$ & $27.472(8.3425)$ & $8.7665(3.3463)$ & $18.256(6.2528)$ \\
\hline fe 1764 & $11.641(11.069)$ & $-0.748(4.4323)$ & $11.701(8.8554)$ \\
\hline ma65 & $33.076(10.924)$ & $2.9609(3.5264)$ & $28.991(9.0275)$ \\
\hline fea65 & $37.021(14.871)$ & $22.209(6.9438)$ & $15.796(10.753)$ \\
\hline \multicolumn{4}{|c|}{ Children School Enrollment } \\
\hline elmnt612 & $18.424(4.1371)$ & $4.2742(2.0020)$ & $12.656(3.6137)$ \\
\hline postelmnt612 & $3.2421(4.9916)$ & $0.0798(2.1865)$ & $2.9676(4.0101)$ \\
\hline elmnt 1316 & $8.5194(6.9703)$ & $1.3961(2.6811)$ & $5.9059(5.4584)$ \\
\hline postelmnt 1316 & $-5.7328(6.633)$ & $0.4191(4.2374)$ & $-9.3375(3.948)$ \\
\hline
\end{tabular}


Table 2.3 Estimates when hour is total and transitory income is a dummy. (Number of observations $=3622$ )

\begin{tabular}{|c|c|c|c|}
\hline \multirow[b]{2}{*}{ Variable } & Htot & Farm & Non-farm \\
\hline & Estimate (s.e.) & Estimate (s.e.) & Estimate (s.e.) \\
\hline \multicolumn{4}{|l|}{$n$} \\
\hline$Y^{P}$ & $-0.0069(0.0575)$ & $-0.0700(0.043)$ & $0.0932(0.0331)$ \\
\hline$D_{n p}^{T}$ & $8.7606(28.516)$ & $12.110(20.886)$ & $-14.862(15.186)$ \\
\hline \multicolumn{4}{|c|}{ Adult Labour Participation } \\
\hline $\operatorname{mal} 764$ & $27.889(8.3668)$ & $18.609(6.3115)$ & $8.9102(3.3574)$ \\
\hline fel764 & $10.192(11.095)$ & $10.585(8.5349)$ & $-1.659(4.4712)$ \\
\hline ma65 & $32.486(10.996)$ & $28.582(8.7196)$ & $2.4234(3.5430)$ \\
\hline fea65 & $34.726(15.109)$ & $14.035(11.003)$ & $20.738(7.0059)$ \\
\hline \multicolumn{4}{|c|}{ Children School Enrollment } \\
\hline elmnt612 & $16.696(4.6206)$ & $11.402(3.8047)$ & $2.9656(2.2850)$ \\
\hline postelmnt612 & $1.2294(5.3294)$ & $1.4306(4.1852)$ & $-1.2374(2.360)$ \\
\hline elmnt1316 & $7.3254(7.1298)$ & $5.0281(5.6844)$ & $0.4842(2.7902)$ \\
\hline postelmnt1316 & $-6.2529(6.729)$ & $-9.6604(4.113)$ & $-0.2038(4.278)$ \\
\hline
\end{tabular}

Note: $D_{n p}^{T}$ is a dummy variable where it is one for a positive transitory income zero otherwise. 
Table 2.4 Estimates when hour is total and transitory income is divided. (Number of observations $=3622$ )

\begin{tabular}{|c|c|c|c|}
\hline \multirow[b]{2}{*}{ Variable } & Htot & Farm & Non-farm \\
\hline & Estimate (s.e.) & Estimate (s.e.) & Estimate (s.e.) \\
\hline \multicolumn{4}{|l|}{$\wedge$} \\
\hline$Y^{P}$ & $-0.0530(0.0550)$ & $0.1088(0.0423)$ & $-0.0687(0.0302)$ \\
\hline \multicolumn{4}{|l|}{$\wedge$} \\
\hline$Y_{n e g}^{T}$ & $0.0995(0.3171)$ & $0.0555(0.2285)$ & $-0.0577(0.0183)$ \\
\hline$\hat{Y^{T}}$ & & & \\
\hline$Y_{p o s}$ & $-0.0835(0.0614)$ & $0.0808(0.0545)$ & $-0.0170(0.0265)$ \\
\hline \multicolumn{4}{|c|}{ Adult Labour Participation } \\
\hline $\operatorname{ma1764}$ & $27.482(8.3406)$ & $18.240(6.2581)$ & $8.7182(3.3783)$ \\
\hline fel764 & $11.666(11.127)$ & $11.660(8.5687)$ & $-0.8674(4.488)$ \\
\hline $\operatorname{ma65}$ & $33.103(10.981)$ & $28.949(8.7438)$ & $2.8379(3.5077)$ \\
\hline fea65 & $37.064(14.972)$ & $15.728(10.982)$ & $22.011(6.9871)$ \\
\hline \multicolumn{4}{|c|}{ Children School Enrollment } \\
\hline elmnt612 & $18.474(4.4365)$ & $12.596(3.6955)$ & $4.0402(2.1685)$ \\
\hline postelmnt612 & $3.2800(5.1749)$ & $2.9060(4.0068)$ & $-0.1002(2.290)$ \\
\hline elmnt1316 & $8.5449(7.0281)$ & $5.8653(5.6343)$ & $1.2771(2.7388)$ \\
\hline postelmnt1316 & $-5.7189(6.658)$ & $-9.3597(4.108)$ & $0.3541(4.2450)$ \\
\hline
\end{tabular}

Note: $Y_{n e g}^{T}=Y^{T}$ if $Y^{T}$ is less than or equal to zero and $Y_{p o s}^{T}=Y^{T}$ if $Y^{T}$ is greater than zero. 
Table 2.5 Estimates when hour is extra and transitory income is undivided. (Number of observations $=3622$ )

\begin{tabular}{|c|c|c|c|}
\hline \multirow[b]{2}{*}{ Variable } & EXHtot & Farm & Non-farm \\
\hline & Estimate (s.e.) & Estimate (s.e.) & Estimate (s.e.) \\
\hline \multicolumn{4}{|l|}{$\wedge$} \\
\hline$Y^{P}$ & $0.0095(0.0183)$ & $0.0242(0.0076)$ & $-0.0293(0.117)$ \\
\hline \multicolumn{4}{|l|}{ ก } \\
\hline$Y^{T}$ & $-0.0238(0.0212)$ & $0.0500(0.0071)$ & $-0.0162(0.0142)$ \\
\hline \multicolumn{4}{|c|}{ Adult Labour Participation } \\
\hline $\operatorname{mal} 764$ & $8.1428(3.5585)$ & $2.1333(1.0605)$ & $2.0787(1.5391)$ \\
\hline fe1764 & $0.9073(4.3738)$ & $-1.4794(1.292)$ & $2.6332(2.8721)$ \\
\hline ma65 & $8.8820(4.9470)$ & $0.1378(1.1075)$ & $6.6597(3.5074)$ \\
\hline fea65 & $12.581(6.7395)$ & $4.5969(2.6317)$ & $-0.7162(3.756)$ \\
\hline \multicolumn{4}{|c|}{ Children School Enrollment } \\
\hline elmnt612 & $2.6260(1.5936)$ & $0.7786(0.6059)$ & $1.3539(1.0837)$ \\
\hline postelmnt612 & $-0.1910(1.200)$ & $-0.2273(0.632)$ & $-0.4362(1.179)$ \\
\hline elmnt1316 & 1.4985 (2.5097) & $0.4938(1.0401)$ & $0.1498(1.6167)$ \\
\hline postelmnt1316 & $-2.5467(2.632)$ & $-0.2916(1.007)$ & $-3.4164(1.110)$ \\
\hline
\end{tabular}


Table 2.6 Estimates when hour is extra and transitory income is a dummy. (Number of observations $=3622$ )

\begin{tabular}{|c|c|c|c|}
\hline \multirow[b]{2}{*}{ Variable } & EXHtot & Farm & Non-farm \\
\hline & Estimate (s.e) & Estimate (s.e) & Estimate (s.e.) \\
\hline$\hat{Y^{P}}$ & $0.0167(0.0239)$ & $-0.0284(0.0115)$ & $0.0280(0.0098)$ \\
\hline$D_{n p}^{T}$ & $5.8019(12.525)$ & $6.4523(6.0794)$ & $-2.6376(4.6805)$ \\
\hline \multicolumn{4}{|c|}{ Adult Labour Participation } \\
\hline $\begin{array}{l}\text { mal764 } \\
\text { fe1764 } \\
\text { ma65 } \\
\text { fea65 }\end{array}$ & $\begin{array}{ll}8.2371 & (3.7651) \\
0.6684 & (4.5346) \\
8.8206 & (5.1765) \\
12.209 & (6.5850)\end{array}$ & $\begin{array}{l}2.1265(1.6376) \\
2.5904(2.8647) \\
6.6941(3.5122) \\
-0.7751 \quad(3.705)\end{array}$ & $\begin{array}{l}2.1470(1.0651) \\
-1.5945(1.350) \\
0.0647(1.0818) \\
4.4061(2.6664)\end{array}$ \\
\hline \multicolumn{4}{|c|}{ Children School Enrollment } \\
\hline $\begin{array}{l}\text { elmnt612 } \\
\text { postelmnt612 } \\
\text { elmnt1316 } \\
\text { postelmnt1316 }\end{array}$ & $\begin{array}{l}2.3881 \quad(1.8359) \\
-0.5120(2.032) \\
1.3358(2.5008) \\
-2.5693(2.654)\end{array}$ & $\begin{array}{l}1.3703(1.1240) \\
-0.4804(1.216) \\
0.1614(1.7572) \\
-3.3479(1.088)\end{array}$ & $\begin{array}{l}0.6047(0.6976) \\
-0.3977(0.661) \\
0.3728(1.0703) \\
-0.3765(1.008)\end{array}$ \\
\hline
\end{tabular}

Note: $D_{n p}^{T}$ is a dummy variable where it is one for a positive transitory income zero otherwise. 
Table 2.7 Estimates when hour is extra and transitory income is divided. (Number of observations $=3622$ )

\begin{tabular}{|c|c|c|c|}
\hline \multirow[b]{2}{*}{ Variable } & EXHtot & Farm & Non-farm \\
\hline & Estimate (s.e.) & Estimate (s.e.) & Estimate (s.e.) \\
\hline \multicolumn{4}{|l|}{$\wedge$} \\
\hline$Y^{P}$ & $0.0023(0.0220)$ & $0.0303(0.0120)$ & $-0.0231(0.0192)$ \\
\hline \multicolumn{4}{|l|}{$\wedge$} \\
\hline$Y_{n e g}^{T}$ & $-0.1178(0.1370)$ & $-0.0485(0.0128)$ & $-0.0428(0.0031)$ \\
\hline$Y_{p o s}^{T}$ & $-0.0112(0.0261)$ & $0.0445(0.0118)$ & $0.0023(0.0084)$ \\
\hline \multicolumn{4}{|c|}{ Adult Labour Participation } \\
\hline $\operatorname{mal} 764$ & $8.2118(3.7743)$ & $2.0885(1.6259)$ & $2.1439(1.0661)$ \\
\hline fe1764 & $1.0778(4.5994)$ & $2.6565(2.9260)$ & $-1.4543(1.3482)$ \\
\hline $\operatorname{ma} 65$ & $9.0575(5.1726)$ & $6.6840(3.5192)$ & $0.1635(1.0810)$ \\
\hline fea65 & $12.865(6.5610)$ & $-0.6772(3.760)$ & $4.6390(2.6554)$ \\
\hline \multicolumn{4}{|c|}{ Children School Enrollment } \\
\hline elmnt612 & $2.9598(1.7646)$ & $1.4000(1.1355)$ & $0.8281(0.6653)$ \\
\hline postelmnt612 & $0.0660(1.9778)$ & $-0.4003(1.185)$ & $-0.1886(0.636)$ \\
\hline elmnt 1316 & $1.6683(2.4637)$ & $0.1741(1.7561)$ & $0.5200(1.0630)$ \\
\hline postelmnt1316 & $-2.4540(2.598)$ & $-3.4017(1.0862)$ & $-0.2757(0.998)$ \\
\hline
\end{tabular}

Note: $\hat{Y_{n e g}^{T}}=\hat{Y^{T}}$ if $\hat{Y^{T}}$ is less than or equal to zero and $\hat{Y_{p o s}^{T}}=\hat{Y^{T}}$ if $\hat{Y^{T}}$ is greater than zero. 
Appendix 2A Estimates of the reduced form equation of total hours (Number of observations $=3622$ )

\begin{tabular}{|c|c|c|c|}
\hline \multirow[b]{2}{*}{ Variable } & Htot & Farm & Non-farm \\
\hline & Estimate (s.e.) & Estimate (s.e.) & Estimate (s.e) \\
\hline \multicolumn{4}{|l|}{$\wedge$} \\
\hline$Y^{T}$ & $0.0874(0.0347)$ & $0.3246(0.0159)$ & $-0.0288(0.0296)$ \\
\hline \multicolumn{4}{|c|}{ Life-cycle stages of household composition by age, gender and education level : } \\
\hline $\operatorname{mal} 417$ & $-19.134(22.350)$ & $-9.4205(8.869)$ & $-5.0066(17.956)$ \\
\hline fel417 & $-29.249(23.335)$ & $-16.794(10.028)$ & $-11.101(17.009)$ \\
\hline ma1864 & $-65.928(87.448)$ & $-20.061(24.182)$ & $-11.718(76.008)$ \\
\hline fel 1864 & $-28.171(13.556)$ & $-18.503(8.996)$ & $-32.977(10.675)$ \\
\hline mal 864prim & $61.971(87.697)$ & $16.391(24.421)$ & $3.5363(76.027)$ \\
\hline mal864sec & $54.963(87.330)$ & $11.703(24.270)$ & $-0.2419(75.989)$ \\
\hline mal 864posec & $53.746(89.543)$ & $19.958(27.820)$ & $-6.3493(76.754)$ \\
\hline fe1864prim & $11.904(14.255)$ & $7.0168(9.2072)$ & $16.400(11.086)$ \\
\hline fel $1864 \mathrm{sec}$ & $1.1848(12.867)$ & $11.791(9.0277)$ & $0.9476(9.1824)$ \\
\hline fel 1864 posec & $0.0000(12.597)$ & $0.0000(8.6483)$ & $0.0000(10.052)$ \\
\hline ma65 & $-1.4902(2.430)$ & $-3.3388(1.144)$ & $-5.1238(1.860)$ \\
\hline fea65 & $-3.2796(3.161)$ & $-3.9210(1.561)$ & $-7.4790(2.662)$ \\
\hline \multicolumn{4}{|c|}{ Land ownership variables : } \\
\hline rntlnd & $-82.457(75.744)$ & $-36.440(23.345)$ & $-42.483(62.057)$ \\
\hline ownlnd & $-15.945(81.518)$ & $-21.933(27.680)$ & $-11.301(67.895)$ \\
\hline \multicolumn{4}{|c|}{ Adult Labour Participation } \\
\hline $\mathrm{mal764}$ & $24.085(8.349)$ & $7.4619(3.2929)$ & $15.184(6.1305)$ \\
\hline fel 164 & $11.414(11.044)$ & $-0.1915(4.235)$ & $11.544(8.3918)$ \\
\hline ma65 & $51.471(21.175)$ & $15.519(9.1411)$ & $32.477(14.455)$ \\
\hline fea65 & $39.439(17.778)$ & $25.287(7.5247)$ & $11.531(13.825)$ \\
\hline \multicolumn{4}{|c|}{ Children School Enrollment } \\
\hline elmnt612 & $36.465(4.6522)$ & $18.146(2.4171)$ & 30.007 (3.9034) \\
\hline postelmnt612 & $32.916(6.7418)$ & $19.564(3.0257)$ & $33.263(5.3827)$ \\
\hline elmnt1316 & $17.786(14.813)$ & $13.533(4.9568)$ & $17.869(11.225)$ \\
\hline postelmnt1316 & $-7.1391(18.419)$ & $15.758(11.557)$ & $-4.9526(11.245)$ \\
\hline
\end{tabular}


Appendix 2B Estimates of the reduced form total extra hours equation (Number of observations $=3622$ )

\begin{tabular}{|c|c|c|c|}
\hline \multirow[b]{2}{*}{ Variable } & EXHtot & Farm & Non-farm \\
\hline & Estimate (s.e.) & Estimate (s.e.) & Estimate (s.e) \\
\hline$Y^{T}$ & $-0.0164(0.0156)$ & $0.0116(0.0054)$ & $-0.0113(0.0106)$ \\
\hline \multicolumn{4}{|c|}{ Life-cycle stages of household composition by age, gender and education level : } \\
\hline $\operatorname{ma1417}$ & $-3.3448(0.7995)$ & $-3.5292(2.8822)$ & $0.9435(6.0103)$ \\
\hline fe 1417 & $-9.0242(8.1557)$ & $-4.0219(2.3946)$ & $-4.5034(3.9448)$ \\
\hline $\operatorname{ma1864}$ & $-10.895(29.972)$ & $-0.2035(2.7473)$ & $-8.5475(2.5996)$ \\
\hline fe1864 & $-14.176(5.6594)$ & $-3.3888(2.368)$ & $-5.7099(2.7373)$ \\
\hline ma1864prim & $7.7338(5.2272)$ & $1.2177(2.8355)$ & $6.1877(2.8260)$ \\
\hline ma1864sec & $5.1100(29.879)$ & $0.5014(2.8230)$ & $3.8846(2.4121)$ \\
\hline ma1864posec & $4.1171(30.429)$ & $0.0012(2.8221)$ & $0.0034(2.3450)$ \\
\hline fe1864prim & $5.9193(5.7590)$ & $0.8344(2.4447)$ & $1.2614(2.8126)$ \\
\hline fe1864sec & $4.2195(5.4275)$ & $1.3581(2.2836)$ & $-2.1340(2.4101)$ \\
\hline fe1864posec & $0.0000(5.1634)$ & $0.0000(2.8221)$ & $0.0000(2.4930)$ \\
\hline $\operatorname{ma65}$ & $-2.4627(1.039)$ & $-0.9592(0.3603)$ & $-2.1002(0.6427)$ \\
\hline fea65 & $-3.0896(1.333)$ & $-1.0682(0.4701)$ & $-2.9213(0.8670)$ \\
\hline \multicolumn{4}{|c|}{ Land ownership variables: } \\
\hline rntlnd & $-26.610(25.386)$ & $-2.7044(4.9635)$ & $-17.508(9.0403)$ \\
\hline ownlnd & $-3.9594(26.488)$ & $0.0015(3.1627)$ & $0.0004(7.7432)$ \\
\hline \multicolumn{4}{|c|}{ Adult Labour Participation } \\
\hline mal764 & $7.0067(3.8172)$ & $1.8628(1.0483)$ & $1.2758(1.5586)$ \\
\hline fel 1764 & $1.2977(4.6359)$ & $-1.3657(1.307)$ & $2.8217(3.0838)$ \\
\hline $\operatorname{ma65}$ & $14.029(7.6827)$ & $3.8387(2.3463)$ & $7.4641(3.7402)$ \\
\hline fea65 & $13.236(8.2580)$ & $5.5896(2.9102)$ & $-1.5350(4.7655)$ \\
\hline \multicolumn{4}{|c|}{ Children School Enrollment } \\
\hline elmnt612 & $11.252(1.940)$ & $4.3091(0.7421)$ & $5.8141(1.2563)$ \\
\hline postelmnt612 & $14.628(2.6748)$ & $4.6788(0.8762)$ & $6.3706(1.4300)$ \\
\hline elmnt 1316 & $9.0346(4.7301)$ & $4.5546(2.1809)$ & $6.2431(3.4641)$ \\
\hline postelmnt1316 & $2.6502(7.1223)$ & $3.3452(2.8485)$ & $-1.7209(2.604)$ \\
\hline
\end{tabular}


Appendix 2C Descriptive statistics of variables (Number all of observations $=3622$ )

\begin{tabular}{lcc}
\hline Variable & Mean & S.D. \\
\hline \hline Total Income & 552.04 & 475.11 \\
& & \\
Household Hours of Work & Measures (Hours per month) \\
H-tot & 346.80 & 326.14 \\
H-totfarm & 247.44 & 260.11 \\
H-totnfarm & 147.43 & 149.75 \\
H-extot & 51.92 & 59.90 \\
H-exfarm & 41.92 & 83.21 \\
H-exnfarm & 20.32 & 47.10 \\
& & \\
Composition of the Life-cycle Stages of Households \\
Total male & 4.20 & \\
Total female & 3.50 & \\
Total above 16 & 4.30 & \\
Total below 17 & 3.39 & \\
Total household size & 7.69 & \\
& & \\
Adults above 16 & & \\
mal764 & 2.22 & \\
fe1764 & 1.57 & \\
ma65 & 0.30 & \\
fea65 & 0.20 & \\
& & \\
Children School Enrollment & & \\
elmnt612 & 0.95 & \\
postelmnt612 & 0.43 & \\
elmnt1316 & 0.36 & \\
postelmnt1316 & & \\
\hline \hline
\end{tabular}




\section{Appendix 2D Description and definition of Variables}

fe1417 The number of female age forteen or above but less than seventeen.

ma1417 The number of male age forteen or above but less than seventeen.

ma1764 The number of adult male between the age of seventeen and sixty-four.

fe1764 The number of adult female between the ages of seventeen and sixty-four.

ma65 The number of male household members sixty-five and above.

fea65 The number of female sixty-five and above.

elmnt612 The number of children between six and twelve in elementary school enrollment

postelmnt612 The number of children between six and twelve above elementary school.

elmnt1316 The number of children between thirteen and sixteen in elementary school.

postelmnt1316 The number of children between thirteen and sixteen above elementary school.

H-tot The total working hours both on farm and on non-farm activities.

H-totfarm The total working hour on farm.

H-totnfarm The total working hour on non-farm activity.

H-extot The total extra working hour both on farm and on non-farm activities.

H-exfarm The total extra working hour on farm.

H-exnfarm The total extra working hour on non-farm activity. 


\section{Appendix 2E Explanations and definitions of hours of work variables}

H-tot $=$ H-totfarm + H-totnfarm + H-extot

H-totfarm $=$ Total working hours on own-farm (on-farm) + Extra working hours on-farm

H-extot $=$ H-exfarm + H-exnfarm

H-exfarm $=$ Total working hours on usual jobs (farm in this case) above and beyond the eight hours per day

$\mathrm{H}$-exnfarm $=$ Total working hours on secondary jobs above and beyond the eight hours per day 


\section{Chapter 3}

\section{Sociopolitical instability, income shocks and savings of households}

\section{Introduction}

While there are a number of important interconnections between political instability and economic behaviour, in this chapter we are interested in analyzing one of these channels in greater detail. In particular, we are investigating the implications of the threat of political instability on the incentive to save, as something distinct from the fact that political violence may affect income flows themselves across time. By looking at the effect of political instability on household savings, we can also look at how that savings decision is affected by the distribution of income and how both of these feedback on political instability.

In the economic literature, different studies find different, sometimes opposing results for the effect of sociopolitical instability on economic behaviour (e.g., Alesina and Rodrick, 1994, Mauro, 1993 and Venieris and Gupta, 1986). This difference is may be because it is difficult to quantify the nature of the disruptions and/or know how these economies would have evolved in the absence of instability. Nevertheless, while traditional indicators of economic deprivation, such as unemployment or poverty, do not themselves appear to be the primary cause of political instability; such factors appear in combination with some form of political mobilization to result in greater political instability. Poverty itself tends 
to discourage participation in political activity, in part because the opportunity cost of involvement is higher for low-income individuals. Nevertheless, widespread poverty or unemployment cutting along ethnic or group identity lines undoubtedly generates trouble both for an existing political regime and for the economy as a whole. In our analysis, we follow the standard practice in economics of treating the presence of political instability as exogenous to the problem of individual choice. That is, we assume that while political instability will impact on the maximizing choices made by the individual, individuals will not take the feedback from economic choices to political instability into account when making their individual maximizing decisions. Nevertheless, we look for independent causes of political instability in the difference in the distribution of income across regions and across time.

One of the two data sets used to test our hypotheses comes from the World Bank's Peru Living Standards Survey of income and expenditure. It also includes information on household demographic setup, income distribution and numbers of households surveyed by region for the year we are considering. The other data is used in our work to estimate the size of these separate effects on both political instability and savings. In the first paper of this thesis when we analyzed Peruvian rural household savings, both the income distribution situation and the sociopolitical environment were not considered. In this paper, on the other hand, we hypothesize that sociopolitical instability (SPI) will be a significant deterrent to household savings. Hence this chapter represents a first attempt to quantify the size of the effect of SPI on savings and the effect of all other variables mentioned above on 
both SPI and savings.

We begin by setting out a theoretical model of how political instability could be expected to affect the household savings rate. Aggregation to the level of the nation then allows different types of distribution effects to be introduced into the model. From this exercise, empirical model of savings based on political instability is derived. Finally, the results of our empirical work are presented and interpreted. 


\section{Theoretical Background}

In traditional economic theory, the projected paths of savings, investment and economic growth through time are analyzed in the context of a constant secure economic environment. More generally, however, the effects of political instability and political violence can be reflected as a change in one or more of the ceteris paribus terms underlying the household's intertemporal optimizing choice. In this way changes in the SPI allow us to analyze the new paths that these economic variables, savings in particular, take more generally. In our analysis, increases in political instability are seen as increasing the individual rate of time preference and the analytical question becomes whether this link results in saving-increasing or decreasing behaviour. In our model political instability (SPI), whether overtly violent or not, will be saving-decreasing. Hence any increase in the level of political stability that is widely felt throughout the economy will provide the economy with conditions that deter savings and economic expansion.

As an example of how considerations of political instability can add insight into traditional economic theory, consider the effect of income redistribution under conditions when the savings rate increases with the level of personal income. Under traditional reasoning, any redistribution in favour of the rich would increase savings and with it the rate of accumulation and rate of economic growth. However, when we broaden the horizon of our analysis to consider the feedback of such policies on political instability and hence the willingness to save, the overall answer may be quite different. Because policies that 
increase the income share of the wealthy can provoke the middle class and poor, the concomitant rise in political instability can more than wipe out the initial advantage given by incremental amounts of savings and investment to growth. In such cases we have two interrelated questions to answer: first, does income inequality lead to a measured increase in the SPI; and second, does the increase in SPI affect savings and so growth?

Intuitively, one would expect that the answer to both questions would be positive. Unequal societies are more likely to be politically unstable with greater political instability, and a higher SPI, both increases the value of having future output today and lowers the level of security associated with realizing real returns in the future. They both discourage savings and economic growth. Therefore, these two separate but interrelated effects that feedback from inequality to SPI, and SPI to savings are developed in a single-equation system derived below. 


\section{Derivation of the model}

Considerable attention has been devoted in the economics literature-economic development (Todaro and Smith, 2003), transition and political economics (Hibbs, 1973, Alesina and Perotti, 1996, and Carmignani, 2003), economic growth (Barro, 1991, Kwabena and Traynor, 1999) - to the analysis of the macroeconomic consequences of uncertainty and SPI. In Carmignani (2003) theoretical predictions and empirical evidence on the role of SPI for economic growth is discussed in detail. In all of these studies, variables such as savings, investment and/or growth use the notions of the security of private property rights, the relative efficiency of the legal system to derive empirical predictions from theoretical models. Most if not all of these models predict a negative correlation between SPI and savings and/or investment and between SPI and output growth.

For our part, we start by using theory to empirically develop a single-equation system of savings as function of SPI, income distribution and change in income. Part of this model was first developed by Venieris \& Gupta (1986) of San Diego State University, and subsequently used by Gupta (1990), Barro (1991) and Alesina and Perotti (1996). Each of these authors has used an index of SPI as the explanatory variable in a regression equation in which the dependent variable is output-growth, savings, or investment. In testing our basic hypothesis we treat savings as a function of SPI and the income distribution and then estimate their effect on savings. 
Assume the household income stream is normally distributed. A saving equation that is linear in income and all the right hand side variables mentioned above can be obtained, by maximizing a lifetime utility function that is additively separable over time and has either a quadratic or a constant-absolute risk-aversion (CARA) form. Contemporary consumer theory assumes that observed consumer behavior is the result of an attempt by rational consumers to maximize utility by allocating a lifetime stream of earnings to an optimum lifetime pattern of consumption.

To formulate the problem in a workable manner, let us begin with a single household as a consumer unit with one good who tries to maximize lifetime utility. Let us further simplify the problem by considering a two-period case in which the household chooses consumption $c_{1}$ in the first period and $c_{2}$ in the second to maximize the following $\log$ utility function:

$$
U\left(c_{1}, c_{2}\right)=\ln c_{1}+\frac{1}{1+\rho} \ln c_{2}
$$

Subject to the budget constraint:

$$
\begin{aligned}
& c_{1}+s_{1}=Y_{1} \\
& c_{2}=(1+r) s_{1}+Y_{2}
\end{aligned}
$$

Substituting $c_{1}=Y_{1}+\frac{Y_{2}}{1+r}-\frac{c_{2}}{1+r}$ into equation (3.1) and maximizing gives the following consumption and saving expressions.

$$
c_{2}=\left(\frac{1+r}{1+\rho}\right) c_{1}
$$




$$
c_{1}=\left(\frac{1+\rho}{2+\rho}\right)\left[Y_{1}+\frac{Y_{2}}{1+r}\right]
$$

Where $c_{1}$ and $c_{2}$ are levels of consumption in the first and in the second periods, respectively; $\rho$ is the rate of time preference, a number between 0 and 1 ; and $\mathrm{r}$ is the interest rate. Therefore, $\frac{1}{1+r}$ is the discount rate. $Y_{1}$ is household income in the first period and $s_{1}$ is first period household saving. The model implies that as long as $\mathrm{r}$ and $\rho$ are constant, as income increases saving will increase proportionately. Alternatively, (3.3) can be rewritten as $c_{1}=\left(\frac{1+\rho}{2+\rho}\right) w_{1}$ to illustrate that consumption is proportional to wealth.

By dividing both sides of equation (3.3) by $\mathrm{Y}_{1}$, we find,

$$
\frac{c_{1}}{Y_{1}}=\left(\frac{1+\rho}{2+\rho}\right)\left[1+\left(\frac{Y_{2}}{Y_{1}}\right)\left(\frac{1}{1+r}\right)\right]=\left(\frac{1+\rho}{2+\rho}\right)\left[1+\left(1+\frac{Y_{2}-Y_{1}}{Y_{1}}\right)\left(\frac{1}{1+r}\right)\right](3
$$

Since in this model $s / Y_{1}=1-c_{1} / Y_{1}$

$$
\frac{s}{Y_{1}}=1-\left(\frac{1+\rho}{2+\rho}\right)\left[1+\left(1+\frac{Y_{2}-Y_{1}}{Y_{1}}\right)\left(\frac{1}{1+r}\right)\right] \text {. }
$$

The household savings rate is then a function of the rate of time preference, $\rho$, the expected growth rate of income, $\frac{\Delta Y}{Y}$, the market rate of interest, $r_{1}$, and the tastes of the households (as embodied in the form of the utility function). Writing this in general form, the savings rate for region $\mathrm{m}$ is, 
$\left(\frac{S}{Y}\right)_{m}=\mathrm{f}[\rho, \Delta \mathrm{Y} / \mathrm{Y}, \mathrm{r}$, tastes $]$, where we can predict from equation 3.5 of the model that:

$$
\begin{aligned}
& \frac{\partial\left(\frac{s}{Y_{1}}\right)}{\partial \rho}=-\frac{1}{(2+\rho)^{2}}\left[1+\left(1+\frac{\Delta Y}{Y_{1}}\right)\left(\frac{1}{1+r}\right)\right]<0 \\
& \frac{\partial\left(\frac{s}{Y_{1}}\right)}{\partial\left(\frac{\Delta Y}{Y_{1}}\right)}=-\left(\frac{1+\rho}{2+\rho}\right)\left(\frac{1}{1+r}\right)<0 \\
& \frac{\partial\left(\frac{s}{Y_{1}}\right)}{\partial r}=\left(\frac{1+\rho}{2+\rho}\right)\left(1+\frac{\Delta Y}{Y_{1}}\right)(1+r)^{-2}>0
\end{aligned}
$$

By aggregating across the households in one region, an aggregate savings rate can be determined. That is,

$$
\frac{S}{Y}=\frac{1}{K} \sum_{k=0}^{K}\left(\frac{S_{k}}{Y_{1 k}}\right)=1-\sum_{k=0}^{K}\left(\frac{1+\rho_{k}}{2+\rho_{k}}\right)\left[1+\left(1+\frac{\Delta Y_{k}}{Y_{1 k}}\right)\left(\frac{1}{1+r}\right)\right]
$$

The aggregate savings rate is in addition to being a function of the means of the determinants of the individual household's decision, a function of the distribution of all these factors across the $\mathrm{K}$ households in the community.

The general form for region $\mathrm{m}$ can now be rewritten as: 


$$
\left(\frac{S}{Y}\right)_{m}=f\left(\frac{Y_{t}}{Y_{1}}, \frac{\Delta Y_{t}}{Y_{1}}, S P I_{t}, \text { Distribution }\right)
$$

Notice here that we have assumed that both the pure rate of time preference and the interest rate are constant so that changes in $\rho_{t}$ reflect changes in the sociopolitical factors through SPI. This savings rate can be rewritten as a linear form:

$$
\frac{S}{Y}=a_{j}\left(\frac{Y_{j t}}{Y_{t}}\right)+a_{j+1}\left(\frac{\Delta Y_{t}}{Y_{t}}\right)+a_{j+2} S P I
$$

Where a's are proportionality constants, and $\mathrm{j}=1,2,3$ is the population percentile to be explained below.

In the above problem, the household chooses whether to consume today or save for tomorrow in the face of an uncertain sociopolitical environment. Because any kind of potential or actual social disturbance leading to civil unrest will produce a deterioration in this environment and makes future outcomes less certain and less realizable relative to the present. This in turn implies that we can model any increase in instability as an increase in $\rho$ the rate at which households discount the future, usually called the rate of preference. We will use the metric, SPI, as our measure of civil unrest that affects savings (Alesina and Perotti, 1996 have the SPI affect investment instead of savings).

Note again that the phenomena of social unrest also causes the disruption of productive activities and through its effect on expected future profits reduces savings by lowering living standards of the population. In this way a high value of the SPI index implies a high 
degree of uncertainty. In addition, when sociopolitical instability becomes widespread, civil unease makes future economic policy and the protection of property rights even more uncertain in the limit raising the probability that the existing government to be overthrown.

Now, (following Venieris and Gupta, 1986), let us assume that the population of the ith region (where $\mathrm{i}=1,2,3,4$ ) can be divided into $\mathrm{n}$ percentiles and let the level of income received by the $\mathrm{jth}$ population percentile (where $\mathrm{j}=1,2 \ldots \mathrm{n}$ ) be given as $Y_{i j t}$. Furthermore, let $S_{i t}$ be the average household saving of the ith region in year t. $Y_{i t}$ be the income of region $\mathrm{i}$ in the same year. $\Delta Y_{i t}$ be the change in household income in region $\mathrm{i}$ at time $\mathrm{t}$, and $S P I_{i t}$ be a measure of sociopolitical instability for region $\mathrm{i}$. The population is then divided into three groups based on income, where $j=1$ represents the lower income group of a given region representing the lower $40 \%$ of the population, $j=2$ represents the middle $40 \%$, and $\mathrm{j}=3$ represents the upper $20 \%$. These can be denoted as $Y_{i 1}, Y_{i 2}$, and $Y_{i 3}$ respectively (Venieris and Gupta, 1986, pp 875-76).

Using the above information, equation (3.7) can be rewritten as:

$$
\begin{aligned}
& \left(\frac{S}{Y}\right)_{i t}=\sum_{j=1}^{3} a_{j} \theta_{i j t}+a_{4}\left(\frac{\Delta Y}{Y}\right)_{i t}+a_{5} S P I_{i t}+e_{i t}, \\
& \text { Where } \mathrm{i}=1,2,3,4, \mathrm{j}=1,2,3 \text {, and } \theta_{i j t}=\frac{Y_{i j t}}{Y_{i t}}, e_{i t} \text { is a measurement error whose is }
\end{aligned}
$$

zero.

Since, at any given time, the sum of income of all groups must add up to the total national 
income:

$$
Y_{i 1}+Y_{i 2}+Y_{i 3}=Y_{i}
$$

Therefore, $\frac{Y_{i 1}}{Y_{i}}+\frac{Y_{i 2}}{Y_{i}}+\frac{Y_{i 3}}{Y_{i}}=1$ this in turn implies that $\theta_{i 1}=1-\theta_{i 2}-\theta_{i 3}$

Therefore, equation (3.8) can be rewritten as:

$$
\begin{aligned}
\left(\frac{S}{Y}\right)_{i t} & =a_{1} \theta_{i t 1}+a_{3} \theta_{i t 2}+a_{3} \theta_{i t 3}+a_{4}\left(\frac{\Delta Y}{Y}\right)_{i t}+a_{5} S P I_{i t}+e_{i t} \\
& =a_{1}\left(1-\theta_{i t 3}-\theta_{i t 2}\right)+a_{2} \theta_{i t 2}+a_{3} \theta_{i t 3}+a_{4}\left(\frac{\Delta Y}{Y}\right)_{i t}+a_{5} S P I_{i t}+e_{i t} \\
& =a_{1}+\left(a_{2}-a_{1}\right) \theta_{i t 2}+\left(a_{3}-a_{1}\right) \theta_{i t 3}+a_{4}\left(\frac{\Delta Y}{Y}\right)_{i t i}+a_{5} S P I_{i t}+e_{i t}
\end{aligned}
$$

Finally the version of the single savings equation that we are going to test is:

$$
\begin{aligned}
& \left(\frac{S}{Y}\right)_{i t}=\alpha_{1}+\alpha_{2} \theta_{i t 2}+\alpha_{3} \theta_{i t 3}+\alpha_{4}\left(\frac{\Delta Y}{Y}\right)_{i t}+\alpha_{5} S P I_{i t}+e_{i t} \\
& \text { Where, } \alpha_{1}=a_{1}, \alpha_{2}=a_{2}-a_{1}, \alpha_{3}=a_{3}-a_{1}, \alpha_{4}=a_{4} \text { and } \alpha_{5}=a_{5} .
\end{aligned}
$$

In order to test whether SPI affects the savings rate of the income groups differently, we will use specific hypotheses where the interactive terms are SPI and the various income groups. (For a complete specification of the hypotheses refer to Appendix 3A). 


\section{Data and summary of results}

There are three sources for the data used in this research. Data on household saving and GDP come from the World Bank's Peru Living Standards Survey and World Bank's World Tables respectively. Data on income distributions are taken from the World Bank's Peru Living Standard Survey for 1994. Therefore, income and savings measures are expressed in constant 1994 prices for each region. About the third data, however, we recognize that it is hard to measure or quantify SPI, but Keesing's Record of World Events identifies a number of recorded variables. These records have information such as irregular executive dismissals, government actions, riots, political protests, demonstrations, strikes, number of armed (guerilla or other) attacks, death from violence, and assassinations. We then identified and recorded the violent and nonviolent events separately for each region as a time series document. Furthermore, we calculated mean, standard deviation, deviation from the mean and deviation from the mean squared of violent and nonviolent SPI for each region in the past 25 years from 1970 to 1994. (For derivations of these values refer to Appendix 3B).

All sociopolitical actions do not equally affect the economy in general and savings in particular in the same disruptive way. Some events such as democratic government changes, political demonstrations and regular transfer of Ministers or executives involve little or no violence. At the other extreme are more violent ones that involve death, whether from assassination or armed attack. But aside from the size of the effect, both would be 
expected to have a negative effect on savings. In the following tests, we will focus on both violent events and non-violent events separately to show the effect of SPI on regional household income and savings.

Table 3.1 provides a set of estimates of the various combinations of equation (3.9). Each combination represents a slightly different hypothesis regarding the use the SPI in the equation. To see the magnitude of the effect of SPI on saving as reflected by the Marginal Propensity to Save (MPS), we used it with and without interactive terms. As reported in table 3.1 , the result shows, with the exception of the $5^{\text {th }}$ combination, that SPI clearly exerts a negative influence on saving. In all the combination equations (see table $3.1 \mathrm{t}$ values) the negative influence of SPI on saving is not only present, but is also large, stable and statistically significant. The test result of the model, (equation \#1 of table 3.1) with the SPI variable not interacted gives the highest value of $R^{2}$ at 0.568 and $F$ at 48.75 . Therefore, the presence of the interaction terms in the model clearly reduces the correlation coefficient by more that $12 \%$ (comparing equation \#1 and \#5 of table 3.1 ) and one can conclude that both saving and SPI are strongly correlated when there are no interacting terms used. Table 3.2 also shows almost similar results that SPI exerts a negative burden on savings even when SPI is nonviolent. However, the scale of the effect is smaller in the nonviolent case (compare equation \#4 in both tables).

In tables 3.3 and 3.4 we used three different values of violent and nonviolent SPI respectively, which gave three different estimates of the MPS. Column (A) represents the 
MPS values when SPI is equal to the average SPI, column (B) is when SPI is equal to the average SPI minus one standard deviation, and the column at $(\mathrm{C})$ represents the value of SPI which is the average SPI minus one standard deviation squared. The last column, however, provides the mean values of the MPS for each income group in the whole of Peru. These tables also suggest that the middle $40 \%$ income earners group is the highest savings-contributing group at the margin. The result in both tables 3.3 and 3.4 also shows how the changes in MPS due to income distribution appear to be smaller in the case of the nonviolent SPI compared to those that are due to fluctuations in violent SPI. Virtually all values of MPS for all income groups due to violent SPI are greater than those due to nonviolent SPI.

The findings in all four tables for savings are derived using recorded household income and expenditure, which may not reflect accurately actual forgone consumption. Hence, it is wise to note that our estimates could be reversed if the true saving of the upper $20 \%$ income group is sufficiently known. However, since we used recorded income and expenditure measures for both the upper and the lower income groups, the same bias arises in all income groups. It does follow, however, that tables 3.1 and 3.2 or 3.3 and 3.4 capture only the effects of violent or nonviolent SPI on recorded savings of Peruvian households. We will not include unknown or unreported savings that may arise in foreign countries and in foreign currencies. This is often thought to be an important source of savings for the upper income group and we do not have information about it. 
Note that the population percentile used in tables 3.3 and 3.4 are utilized in such a way that when income is between zero and 300 Soles, $\theta_{i t 2}$ and $\theta_{i t 3}$ are both zero. Note that these income groups are also further divided in halves to show their effects on savings and SPI within the group. The same technique was utilized for all three income groups. When income is between 301 and 1000 Soles (the middle $40 \%$ income group), $\theta_{i t 1}$ and $\theta_{i t 3}$ are zero. Finally, when income is above a 1001 (the upper $20 \%$ income group), $\theta_{i t 1}$ and $\theta_{i t 2}$ are both zero.

The results in tables 3.3 and 3.4 show that the effect of SPI when it is violent (table 3.3) has higher effect on all income groups than when it is nonviolent (table 3.4). However, this is not counterintuitive result because according to our data the frequency of occurrence of the nonviolent SPI, within the 25 years we are considering, was much higher than that of the violent SPI. We also believe, because much of the assassinations, gorilla attacks, bombings and coups (much of the violent SPI) occurred around Lima and Callao and most of the PLSS data collected by the World Bank also focused around this province, therefore, this also had an effect on our findings. The general trend, however, that the profound effect of SPI (violent or nonviolent) on savings and income distribution on savings is the same in both cases. 


\section{Conclusions}

SPI and income distribution (defined by the three income variables) have a profound effect on the savings ratio, whereas, change in income has an insignificant effect.

We believe that a distribution of income in favor of the low or middle-income group at the expense of the upper income bracket is beneficial in Peru for two reasons. First, this measure would increase aggregate savings, which in turn increases investment and economic growth in the country. Second, our finding indicates that the low and middleincome group of society contributes the bulk of savings in the country. At this point we like to suggest for future research to see if it is feasible for a government in Peru to adopt a policy that rewards the middle or lower income groups to stimulate the economy.

Our result also shows a great deal of income inequality exists in Peru. Income inequality increases sociopolitical instability, which in turn decreases investment by decreasing aggregate savings. In general, two contradictory conclusions may arise from our estimations and from the traditional economic theory perspective. First, adopting fiscal redistribution, say, increasing the tax burden on the rich and investors reduces the propensity to save or invest and use domestic financial intermediaries and, therefore, hurts the economy. Second, however, the same policy may reduce social tensions and, as a result, may create a sociopolitical climate more conducive to productive activities and capital accumulation which is necessary for economic growth. Therefore the net effect of 
such policies has to weigh the opportunity cost of this type of taxation against the benefits of reduced sociopolitical instabilities and that wasn't the purpose of this paper.

The most important key findings of our research here are that savings are significantly affected by sociopolitical instability and that a higher income inequality could lead to a higher social unrest. 


\section{References}

Alberto Abadie and Javier Gardeazabal, "The Economic costs of Conflict: A Case Study of the Basque Country." The American Economic Review, Vol. 93 No. 1, March 2003, Pp. 113-132

Alberto Alesina and Roberto Perotti, "Income distribution, political instability, and Investment," European Economic Review, Vol. 40, 1996, pp. 1203-1228

Alberto Alesina and Dani Rodrik, "Distributive politics and economic growth, "Quarterly Journal of Economics. 1994, Vol. 109, pp. 465-490

Alberto Alesina, Sule Ozler, Nouriel Roubini, and Phillip Swagel, "Political Instability and Economic Growth," Journal of Economic Growth, June 1996, Vol.1 \#2, pp.189-211.

Robert J. Barro, "Economic Growth in a cross-section of countries," Quarterly Journal of Economics. May 1991, Vol. 106, pp. 407-444.

Fabrizio Carmignani, "Political Instability, Uncertainty and Economics," Journal of Economic Surveys, 2003, Vol. 17, No. 1. Pp. 1-54

Dipak K. Gupta, The Economics of Political Violence: the effect of political instability on economic growth. Praeger, New York, 1990.

Gyimah-Brempong Kwabena and Thomas L. Traynor, "Political Instability, Investment and Economic Growth in Sub-Saharan Africa," Journal of African Economics, March 1999, Vol. 8 No. pp. 52-86

Douglas A. Hibbs, Mass Political Violence: A cross-sectional Analysis. New York: Waley and Sons, 1973. 
Keesing's Record of World Events: Peru 1973-1995.

Alan B. Krueger and Jitka Maleckova, "Education, Poverty, Political Violence and Terrorism: Is there a Causal Connection?" National Bureau of Economic Research, Working Paper 9074. pp. 1-36.

Douglass B. Stewart, and Yiannis P. Venieris, "Sociopolitical Instability and Behavior of Savings in Less-developed Countries." Review Economics and Statistics. November 1985. pp. 557-563.

Michael Todaro and Smith, Economic Development, $8^{\text {th }}$ edition, 2003. Addison Wesley.

Yiannis P. Venieris, and Dipak K. Gupta, "Income Distribution and Sociopolitical Instability as Determinants of Savings: A Cross-sectional Model,“ Journal of Political Economy, 1986, Vol. 94 No 4. Pp 873-883.

The World Bank Development Research Group, Poverty and Human Resources. Peru Living Standards Measurement Survey 1985/86 and 1994. 
Table 3.1 Estimates of the savings function when SPI is violent.

\begin{tabular}{|c|c|c|c|c|c|}
\hline Equation \# & 1 & 2 & 3 & 4 & 5 \\
\hline Constant & $-0.001(-4.85)$ & $-0.026(-2.23)$ & $-0.001(-2.35)$ & $-0.001(-2.38)$ & $-0.002(-6.69)$ \\
\hline$\theta_{i 2}$ & \multicolumn{5}{|c|}{$0.348(41.10) 0.338(40.41) 0.324(35.68) 0.324(36.44) \quad-1.350(-6.25)$} \\
\hline$\theta_{i 3}$ & \multicolumn{5}{|c|}{$0.192(7.67) 0.143(5.18) 0.167(6.77) 0.142(5.64)$} \\
\hline$(\Delta Y / Y)_{i}$ & $0.003(1.80)$ & $-0.004(-1.08)$ & $-0.001(-1.01)$ & $-0.001(-1.61)$ & $-0.076(-4.62)$ \\
\hline$S P I_{i}$ & $-0.009(-5.75)$ & $\cdots$ & $\cdots$ & $\cdots$ & $\cdots$ \\
\hline$\theta_{i 2} S P I_{i}$ & $\cdots$ & $-0.010(-4.86)$ & $\cdots$ & $\cdots$ & $0.175(7.78)$ \\
\hline$\theta_{i 3} S P I_{i}$ & $\ldots$ & $\cdots$ & $-0.011(-4.05)$ & $\ldots$ & $0.160(6.00)$ \\
\hline$\left(\theta_{i 2}+\theta_{i 3}\right) S P I_{i}$ & $\cdots$ & $\cdots$ & $\cdots$ & $-0.010(-4.46)$ & $\cdots$ \\
\hline$R^{2}$ & 0.568 & 0.560 & 0.561 & 0.564 & 0.523 \\
\hline$F$ & 8.75 & 46.50 & 28.40 & 47.42 & 5.44 \\
\hline
\end{tabular}

Note: $t$-values are in parenthesis. Equation 1 through 5 shows results of different combinations of the violent SPI in Equation (3.9). Equations 1 through 5 are derived in Appendix 3A. 
Table 3.2 Estimates of the savings function when SPI is nonviolent.

\begin{tabular}{llcccc}
\hline Equation \# & 1 & 2 & 3 & 4 & 5 \\
\hline \hline Constant & $0.004(3.62)$ & $-0.004(-1.52)$ & $-0.005(-1.49)$ & $-0.005(-1.45)$ & $-0.004(-1.50)$ \\
$\theta_{i 2}$ & $0.338(6.74)$ & $0.495(4.08)$ & $0.139(10.42)$ & $0.273(4.09)$ & $0.373(4.75)$ \\
$\theta_{i 3}$ & $0.164(11.32)$ & $0.331(7.02)$ & $0.373(4.74)$ & $0.466(7.05)$ & $0.500(4.08)$ \\
$(\Delta Y / Y)_{i}$ & $-0.002(-3.72)$ & $-0.003(-4.40)$ & $-0.003(-4.39)$ & $-0.004(-4.40)$ & $-0.004(-5.40)$ \\
$S P I_{i}$ & $-0.002(-4.35)$ & $\ldots$ & $\ldots$ & $\ldots$ & $\ldots$ \\
$\theta_{i 2} S P I_{i}$ & $\ldots$ & $-0.062(-2.98)$ & $\ldots$ & $\ldots$ & $-0.062(-2.96)$ \\
$\theta_{i 3} S P I_{i}$ & $\ldots$ & $\ldots$ & $-0.007(-8.54)$ & $\ldots$ & $0.010(-5.54)$ \\
$\left(\theta_{i 2}+\theta_{i 3}\right) S P I_{i} \ldots$ & $\ldots$ & $\ldots$ & $-0.023(-2.95)$ & $\ldots$ \\
\hline$R^{2}$ & 0.583 & 0.581 & 0.580 & 0.581 & 0.573 \\
$F$ & 12.62 & 12.56 & 12.51 & 12.53 & 10.05 \\
\hline \hline
\end{tabular}

Note: $t$-values are in parenthesis. Equation \# 1 through 5 shows results of different combinations of the nonviolent SPI in Equation (3.9). Equations 1 through 5 are derived in Appendix 3A. 
Table 3.3 Estimates of Marginal Propensity to Save (MPS) at three different values of SPI for each income group.

\begin{tabular}{lllll} 
Income Groups & $\mathrm{A}$ & $\mathrm{B}$ & $\mathrm{C}$ & Avg. MPS \\
\hline$<100$ Soles & 0.987 & 0.968 & 0.168 & 0.708 \\
101 to 300 & 0.988 & 0.975 & 0.322 & 0.762 \\
301 to 500 & 0.316 & 0.344 & 0.202 & 0.287 \\
501 to 1000 & 0.716 & 0.665 & 0.288 & 0.556 \\
1001 to 2000 & 0.211 & 0.198 & 0.078 & 0.162 \\
$>2000$ & 0.092 & 0.207 & 0.028 & 0.109 \\
Total Average & 0.552 & 0.560 & 0.181 & 0.431 \\
\hline
\end{tabular}

Note: We used combination equation \#4 for the above calculation of the effect of SPI on savings based on various income groups. For derivation of equation $\# 4$ refer Appendix $3 \mathrm{~A}$ and for calculation of the three different values of SPI refer Appendix 3B. 
Table 3.4 Estimates of Marginal Propensity to Save (MPS) at three different values of nonviolent SPI for each income group.

\begin{tabular}{lllll}
\hline Income Groups & $\mathrm{A}$ & $\mathrm{B}$ & $\mathrm{C}$ & Avg. MPS \\
\hline \hline$<100$ Soles & 0.013 & 0.078 & 0.091 & 0.063 \\
101 to 300 & 0.053 & 0.048 & 0.056 & 0.044 \\
301 to 500 & 0.125 & 0.091 & 0.134 & 0.158 \\
501 to 1000 & 0.049 & 0.356 & 0.053 & 0.201 \\
1001 to 2000 & 0.168 & 0.072 & 0.033 & 0.111 \\
$>2000$ & 0.061 & 0.028 & 0.071 & 0.063 \\
Total Average & 0.078 & 0.075 & 0.054 & 0.076 \\
\hline \hline
\end{tabular}

Note: We used combination equation $\# 4$ for the above calculation of the effect of SPI on savings based on various income groups. For derivation of equation \#4 refer Appendix $3 \mathrm{~A}$ and for calculation of the three different values of SPI refer Appendix 3B. 


\section{Appendix 3A Derivation of equations \#1 through \#5 that forms the regression model with interaction terms based on specific hypotheses}

The first hypothesis is the bases for all others that will be considered here. That is, first we need to test whether our intuition that the coefficient of SPI in equation 3.9 is less than or equal to zero is correct: $H_{0}: \alpha_{5} \leq 0$

This will give us the original model that was derived in section III. We call it here Equation \#1.

\section{Equation \#1:}

$$
\left(\frac{S}{Y}\right)_{i t}=\alpha_{1}+\alpha_{2} \theta_{i t 2}+\alpha_{3} \theta_{i t 3}+\alpha_{4}\left(\frac{\Delta Y}{Y}\right)_{i t}+\alpha_{5} S P I_{i t}+e_{i t}
$$

The second hypothesis is whether the interaction between SPI and $\theta_{i t 2}$ will give us the required results, that is, $H_{0}: \alpha_{2} \alpha_{5}=\alpha^{\prime}{ }_{5} \leq 0$

This will give us:

\section{Equation \#2:}

$$
\left(\frac{S}{Y}\right)_{i t}=\alpha_{1}^{\prime}+\alpha_{2}^{\prime} \theta_{i t 2}+\alpha_{3}^{\prime} \theta_{i t 3}+\alpha_{4}^{\prime}\left(\frac{\Delta Y}{Y}\right)_{i t}+\alpha_{5}^{\prime}\left(\theta_{2} S P I\right)_{i t}+e_{i t}^{\prime}
$$

The third hypothesis, interaction between SPI and $\theta_{i t 3}, H_{0}: \alpha_{3} \alpha_{5}=\alpha^{\prime \prime}{ }_{5} \leq 0$

This will give us:

\section{Equation \#3:}

$$
\left(\frac{S}{Y}\right)_{i t}=\alpha^{\prime \prime}{ }_{1}+\alpha^{\prime \prime}{ }_{2} \theta_{i t 2}+\alpha^{\prime \prime}{ }_{3} \theta_{i t 3}+\alpha^{\prime \prime}{ }_{4}\left(\frac{\Delta Y}{Y}\right)_{i t}+\alpha^{\prime \prime}{ }_{5}\left(\theta_{3} S P I\right)_{i t}+e^{\prime \prime}{ }_{i t}
$$

The fourth hypothesis, interaction between SPI and $\left(\theta_{i n 2}+\theta_{i t 3}\right)$,

$$
H_{0}:\left(\alpha_{2}+\alpha_{3}\right) \alpha_{5}=\alpha^{\prime \prime \prime}{ }_{5} \leq 0
$$

This gives:

\section{Equation \#4:}

$$
\left(\frac{S}{Y}\right)_{i t}=\alpha^{\prime \prime \prime}{ }_{1}+\alpha^{\prime \prime \prime}{ }_{2} \theta_{i t 2}+\alpha^{\prime \prime \prime}{ }_{3} \theta_{i t 3}+\alpha^{\prime \prime \prime}\left(\frac{\Delta Y}{Y}\right)_{i t}+\alpha^{\prime \prime \prime}{ }_{5}\left(\theta_{2}+\theta_{3}\right) S P I_{i t}+e^{\prime \prime \prime}{ }_{i t}
$$

The fifth hypothesis, interaction between SPI and $\theta_{i t 2}$ plus between SPI and $\theta_{i t 3}$,

$$
H_{0}: \alpha_{2} \alpha_{5}=\alpha_{5}^{V} \leq 0 \text { or } \alpha_{3} \alpha_{5}=\alpha_{5}^{V 3} \leq 0
$$

This gives:

Equation \#5:

$$
\left(\frac{S}{Y}\right)_{i t}=\alpha_{1}^{V}+\alpha_{2}^{V} \theta_{i t 2}+\alpha_{3}^{V} \theta_{i t 3}+\alpha_{4}^{V}\left(\frac{\Delta Y}{Y}\right)_{i t}+\alpha_{5}^{V}\left(\theta_{2} S P I\right)_{i t}+\alpha_{5}^{V 3}\left(\theta_{3} S P I\right)_{i t}+e_{i t}^{V}
$$

The test results are reported in table 3.1 (for violent SPI), and table 3.2 (for non violent SPI). 


\section{Appendix 3B Definition and derivation of the various SPI values}

Sociopolitical instability (SPI) is defined as a social unrest arising from dissatisfaction on the current social or political atmosphere. SPI could be a result of violent or nonviolent events.

Since SPI are difficult to quantify, therefore, we need to define it as a binary variable, where 0 and 1 typically denotes the two values. Let $S P I_{i t}$ be a sociopolitical unrest in region $\mathrm{i}$ at time $\mathrm{t}$, it can be defined as:

\section{$S P I= \begin{cases}1 & \text { if violent or nonviolent event occured } \\ 0 & \text { Otherwise }\end{cases}$}

We had developed a 25 years time-series data of violent and nonviolent events from Keesing's Record of World Events. Since our income and savings data is from 1994 PLSS, the SPI data we chose to use are from 1970 to 1994 . We then calculated the average SPI for every month based on events that occurred for the past 25 years in each region as follows:

\section{Region i:}

$$
\begin{aligned}
& \text { January - Average SPI }=\overline{S P I_{i 1}}=\frac{1}{25} \sum_{t=1}^{25} S P I_{i t}, \mathrm{t}=\operatorname{Jan} 1970, \operatorname{Jan} 1971, \ldots, \mathrm{Jan} 1994 \\
& \text { February - Average SPI }=\overline{S P I_{i 2}}=\frac{1}{25} \sum_{t=1}^{25} S P I_{i t}, \mathrm{t}=\text { Feb1970, Feb1971,..,Feb1994 } \\
& \text { December - Average SPI }=\overline{S P I_{i 12}}=\frac{1}{25} \sum_{t=1}^{25} S P I_{i t}, \mathrm{t}=\operatorname{Dec} 1970, \operatorname{Dec} 1971, \ldots, \operatorname{Dec} 1994
\end{aligned}
$$

The average SPI for this region, therefore, can now be computed as:

$$
\overline{S P I_{i}}=\frac{1}{12} \sum_{m=1}^{12} S P I_{i m}, \mathrm{~m}=\mathrm{Jan}, \mathrm{Feb}, \ldots, \text { Dec }=1,2, \ldots, 12
$$

The standard deviation of SPI is computed as:

$$
s d(S P I)_{i}=\left[\frac{\sum_{m-1}^{12}\left(S P I_{i m}-\overline{S P I_{i}}\right)^{2}}{m-1}\right]^{1 / 2}
$$

In tables 3.3 and 3.4 the various combinations of the SPI variables are used as follows:

In tables 3.3 and 3.4 column $\mathrm{A}, \mathrm{SPI}=\overline{S P I_{i}}$

In tables 3.3 and 3.4 column $\mathrm{B}, \mathrm{SPI}=\overline{S P I_{i}}-s d(S P I)_{i}$

In tables 3.3 and 3.4 column $\mathrm{C}, \mathrm{SPI}=\left(\overline{S P I_{i}}-s d(S P I)_{i}\right)^{2}$ 


\section{Appendix 3C Typical and chronological examples of sociopolitical disruptions in Peru: 1970-1994}

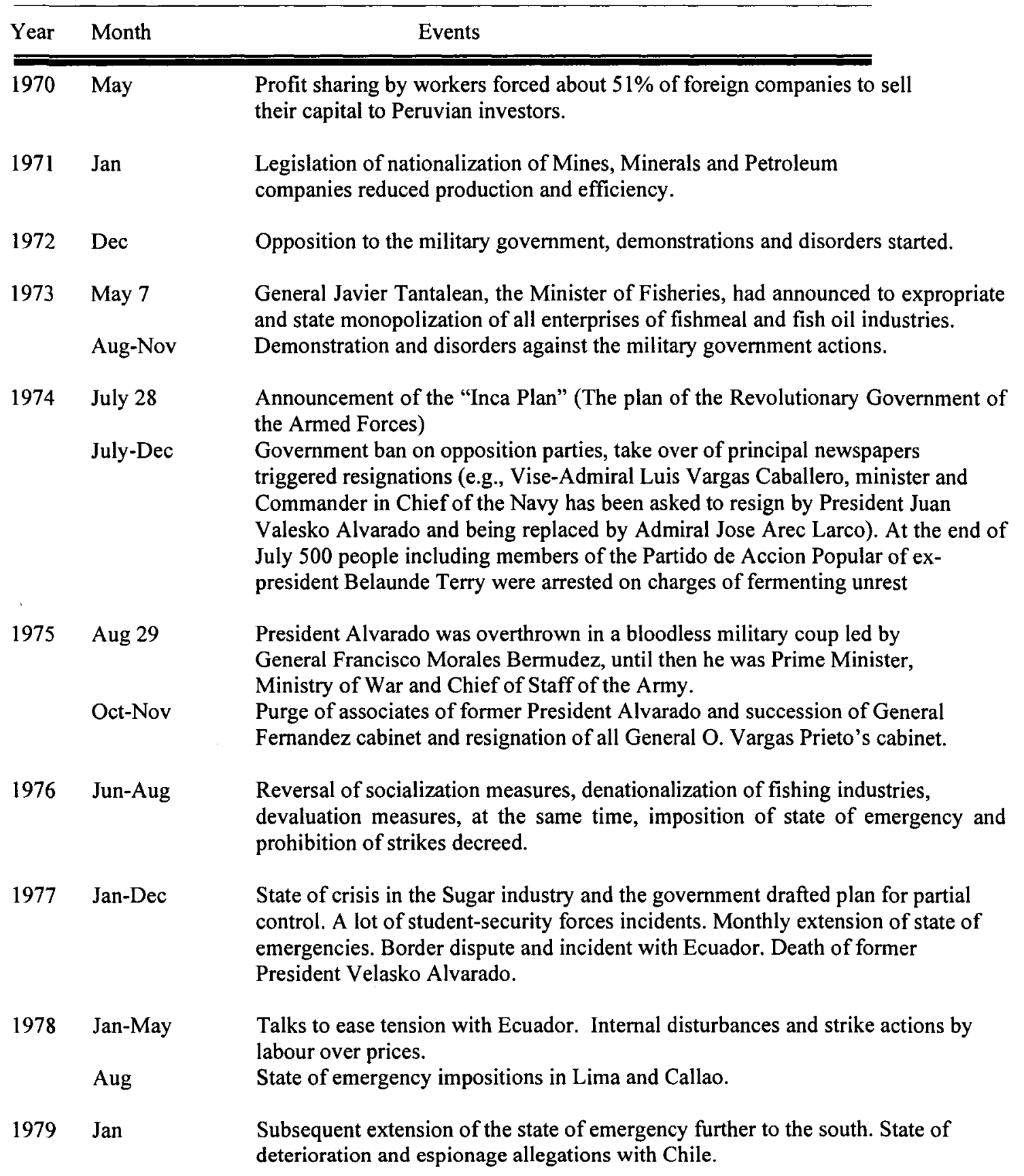


Jul-Oct Intense labour unrest. Strike by teachers and miners. Death of R. Haya de la Torre the American Popular Revolutionary Alliance party's presidential candidate.

1980 May-Jul

1981 Jan

Feb-Apr

Aug

1982 Jan-Dec

1983 Jan-Aug

1984 Jan-Jul

1985 Apr-Jul

1986 Jan

1987 Jul-Sep

1988 May $14-27$

Oct 4-5

Mid-Oct
Election and inauguration of President Belaunde Terry. Flight of 10,000 Cubans into the Peruvian embassy in Havana. Purchase of military aircraft from the Soviets and Soviet aid for power and irrigation projects. State of hostility of Peru towards the military takeover in Bolivia.

Government policy to increase prices, and subsequent strike action against price increase. Bombing and other incidents and then arrests.

Border dispute and outbreak of hostilities with Ecuador, but restoration of diplomatic relations with Chile.

Anti-terrorist legislation due to political violence. Attacks on US institutions in Peru.

Ministerial change and appointment of new Prime Minister. Intensification of terrorist activity in rural areas and in Lima, major incidents attributed to Sendero Luminoso (Shining Path) group. Decision by President Belaunde government to deploy armed forces against guerrillas. Murder of Peruvian journalists.

Extension of guerrilla activities, conflict with security forces, sabotage attacks, state of emergency declarations and involvement of the army in police and security operations. Prison riots. Murder charges against civil guard members.

Sendero Luminoso guerrilla campaign against the government intensified and controversy and increased involvement of armed forces in counter-insurgency. Union opposition towards government economic policy led yet to another strike.

Election and inauguration of President Garcia in the face of election violence, bomb attacks in Lima and shooting of electoral authority. Sandero Luminoso expanded guerrilla activity in all of Peru. Human right violations, disappearances and discoveries of mass graves, allegations against security forces by Amnesty International report.

State of emergency due to food shortage. Government measures to increase agricultural production. Suspension of US aid and relations due to nationalization of Belco Oil Company. Urban guerilla activity in Lima, bombing, attacks on diplomatic targets. Killing of Sendero Luminoso prison inmates further intensified bombing and guerrilla attacks.

State intervention in financial systems, nationalization of banks.

Armed forces massacre 30 to 100 peasants in Cayara (near Ayacucho). Garcia ordered an investigation, but the graves of the victims had been opened up and the bodies removed, no one took responsibility.

Four policemen were killed by Sandero guerrillas in two separate incidents.

The head of Peru's Industrial Bank former Navy Vice-Admiral Geronimo Cafferata shot to death and this prompted President Garcia on Oct 29, to renew for 60 days the state of emergency first imposed in Feb and then extended to 37 of Peru's 172 provinces. 
The biggest clash so far in the eight year guerrilla war, in which 100 Sendero Luminoso guerrillas, 20 soldiers, 68 members of a peasant "self-defense group" were killed.

1990 Apr 8-9

During presidential election a candidate for the United Left Coalition (UI) party Henry Pease was shot and wounded by a police officer. General Enrique Lopez Albujar former Army Chief of Staff defense Minister from Oct 1987 to May 1989 shot to death by three assailants of the left-wing Tupac Amaru Revolutionary Movement (MRTA).

1991 Nov $21 \quad$ Amnesty International report that 250 people had disappeared or had been killed in the "emergency zones" since President Alberto Keinya Fujimori took office in Aug 1990.

Nov MRTA bombed a dozen of banks in Lima and carried a grenade attack on the presidential palace.

Aug A children 12-14 mass graves was discovered by a commission financed by UNICEF in the eastern Amazonian jungles near the Madre de Dios river.

1992 Apr 5

President Fujimori seized absolute power in an army-backed coup, suspending those sections of the constitution, which recognized the authority of the congress and of the judiciary.

Apr 6 He issued a decree that formalized the dissolution of the congress and set an agenda for constitutional reform. A lot countries including Canada suspended their diplomatic relations.

1993 Aug 19 Sandero Luminoso guerrillas massacre 55 Ashaninka-Indians in attacks on seven of their villages, situated near the jungle town of Satipo, $300 \mathrm{Km}$ east of Lima.

1994 Jan 11-13

Canada resumed diplomatic relations with Peru, but the US with hold all economic aid for the 1993 totaling US\$105 million.

Dec Heavy fighting between Peruvian and Ecuadorian troops flared in the disputed border region. In the mean time, on Jan 12 Peruvian state radio reported that the government had extended by yet another 60 days the state of emergency in Lima and Callao due to "obstruction to internal order" in the area. 